\title{
ISLA ISABEL: VIAJEROS, REGISTROS ARQUEOLÓGICOS Y GEOGRAFÍA CULTURAL
}

\author{
LUIS A. BORRERO ${ }^{a}$, FLAVIA MORELLO ${ }^{b}$, MANUEL SAN ROMÁN $^{\mathrm{b}}$, \\ COLIN MCEWAN ${ }^{c} \&$ FABIANA M. MARTIN ${ }^{b}$
}

\section{RESUMEN}

Se presenta la información histórica, etnográfica y arqueológica de la isla Isabel, estrecho de Magallanes, enfatizando su localización en el extremo oriental de las distribuciones conocidas de sitios de cazadores-recolectores marítimos de Patagonia y Tierra del Fuego, Chile. Asimismo se realizaron observaciones tanto tafonómicas como formacionales. Destaca la diversidad de materiales arqueológicos registrados en la isla, que incluyen tanto elementos característicos de cazadores marítimos como terrestres. Finalmente, se considera el lugar que ocupó esta isla en la geografía cultural de la región, discutiendo su relación con otras islas del Estrecho y del continente.

PALABRAS CLAVE: Patagonia, Tierra del Fuego, estrecho de Magallanes, arqueología, cazadoresrecolectores, tafonomía.

\section{ELIZABETH ISLAND: TRAVELERS, ARCHAEOLOGICAL RECORDS AND CULTURAL GEOGRAPHY}

\begin{abstract}
The historic, ethnographic and archaeological information on the Elizabeth Island, Strait of Magellan, Chile is presented, with an emphasis on the location of the island on the eastern limit of the distribution of patagonian and fuegian maritime hunter-gatherers. Taphonomic and formational observations were also made. The diversity of archaeological materials recorded on the island is highlighted, including elements attributable to both maritime and terrestrial hunter-gatherers. Finally, the place of the island within the cultural geography of the region is considered, discussing its relationships with other islands of the Magellan Strait and the continent.

KEY WORDS: Patagonia, Tierra del Fuego, Strait of Magellan, archaeology, hunter-gatherers, taphonomy.

a CONICET-IMHICIHU, Argentina. $\Sigma$ laborrero2003@yahoo.com

b Centro de Estudios del Hombre Austral, Instituto de la Patagonia, Universidad de Magallanes. flavia.morello@umag.cl; manuel. sanroman@umag.cl; fabiana.martin@umag.cl

c Dumbarton Oaks, Precolumbian Studies, USA. McEwanC@doaks.org
\end{abstract}




\section{INTRODUCCIÓN}

La isla Isabel se encuentra en el estrecho de Magallanes -Chile- entre la bahía de San Bartolomé, el paso Real, el paso Pelícano y el canal Reina (Riso Patrón, 1924, p. 432). Esta localización es un punto de inflexión geográfica particular, al oeste de la Segunda Angostura, en el extremo norte de la península Brunswick y en donde el Estrecho se proyecta como vía hacia el sur fueguino. Ubicada a menos de un kilómetro del continente, es una bisagra que se abre al territorio insular de Tierra del Fuego estando aún en la franja de estepa, mas a un paso de la transición ambiental al bosque, las planicies orientales precordilleranas y el archipiélago fueguino-patagónico (Fig. 1).

Localizada cerca de la isla Marta y separada de la isla Magdalena por el paso de la Reina, forma parte de una importante zona productiva del estrecho de Magallanes, con condiciones climáticas de baja estacionalidad. La isla, de unos $35 \mathrm{~km}^{2}$ de superficie, presenta una topografía de relieves suaves, con una altura máxima de $57 \mathrm{msnm}$, asociada con un campo de drumlins (Marangunic, 1974; Magazzù et al. 1996; Santana et al. 2001; Rolfo \& Ardrizzi, 2007, p. 437).

La vegetación es esteparia y la abundancia de vertebrados muy baja (Ortiz Troncoso, 1971, p. 24). La ausencia de mamíferos en general fue notada por Ibar Sierra (2002[1877], p. 62), mientras que Coppinger destacó la ausencia de Ctenomys sp. (Coppinger, 2007[1883]). En el contexto reciente de explotación ganadera, las ovejas se han integrado totalmente al paisaje. Recientes observaciones tafonómicas realizadas en transectas en el siglo XXI -presencia de huesos de oveja con marcas, excrementos- nos sugirieron la presencia de zorros, información que fue corroborada por el puestero (Aladino Nicucheo, com. pers., 2003). Se trata de una adición reciente -zorros grises (Lycalopex griseus)- además de unos pocos individuos de Pterocnemia pennata. Sobre estos últimos nos informaron que ninguno llegó a morir en la isla y no hemos identificado huesos que se le puedan atribuir ${ }^{1}$. Debido a la cercanía de la lobería de isla Marta (Sielfeld et al. 1978; Sielfeld, 1983), llama la atención

1 En 1599-1600 Van Noort, escribiendo sobre las islas "Penguin", que podían incluir o no a isla Isabel, menciona la palabra talcke que, según Cooper (1967[1917], p. 115) se refiere a un ñandú. Posteriormente hay una referencia la observación de Brassey (1891 p. 125) acerca de no haber observado los esperados mamíferos marinos entre Isabel y Magdalena en octubre de 1876 cuando recorrieron el estrecho con el yate Sunbeam (Chevalier, 2000, p. 76). Se encuentra agua dulce actualmente en la isla (Ortiz Troncoso, 1971, p. 24). Ya se había observado la existencia de "lagunillas de estación" de agua dulce en hondonadas en el siglo XIX (Ibar Sierra, 2002[1877], p. 61) o de ciénagas desecadas cuyo suelo se encuentra, en algunas partes, cubierto por costras de sal en el siglo XVIII (Bouganville, 2005[1772], p. 174), o lagunas secas (Lambart Price, 1877, p. 59), además de que in several places, at about fifty feet from the summit of the cliff, streams of water oozed out from the seams (Coppinger, 2007[1883], p. 39).

Sobre la base de la información histórica, etnográfica y arqueológica acerca de la isla Isabel se organizó un proyecto conjunto entre el Instituto de la Patagonia, el CONICET-IMHICIHU y el British Museum, que se concentró en relacionar depósitos arqueológicos con los registros y observaciones de los distintos viajeros, estudiar los cambios ocurridos en los depósitos arqueológicos entre las sucesivas visitas registradas hasta nuestro trabajo y analizar depósitos arqueológicos relacionables con el límite oriental en la distribución de poblaciones canoeras (Bird, 1938, p. 259). Entre otras cosas se buscó analizar la geografía histórica e importancia de la isla en el desarrollo de la arqueología patagónica, reevaluar lo hecho por Bird -distribución espacial, profundidad temporal-, ponderar características culturales del registro arqueológico y situación geográfica particular de la isla en vistas a discutir las interacciones de sus ocupantes con los territorios vecinos.

\section{HISTORIA}

La historia de la isla Isabel deriva básicamente de una serie de cortas visitas de cazadoresrecolectores realizadas a lo largo de miles de años, a lo que se agregaron breves visitas de diversos viajeros, exploradores y arqueólogos, además de una instalación ganadera permanente desde fines

relacionada con las excavaciones de tripulantes de H.M.S. Challenger (Tizzard et al. 1885, p. 872). No conocemos más elementos que relacionen estas aves con las islas. 

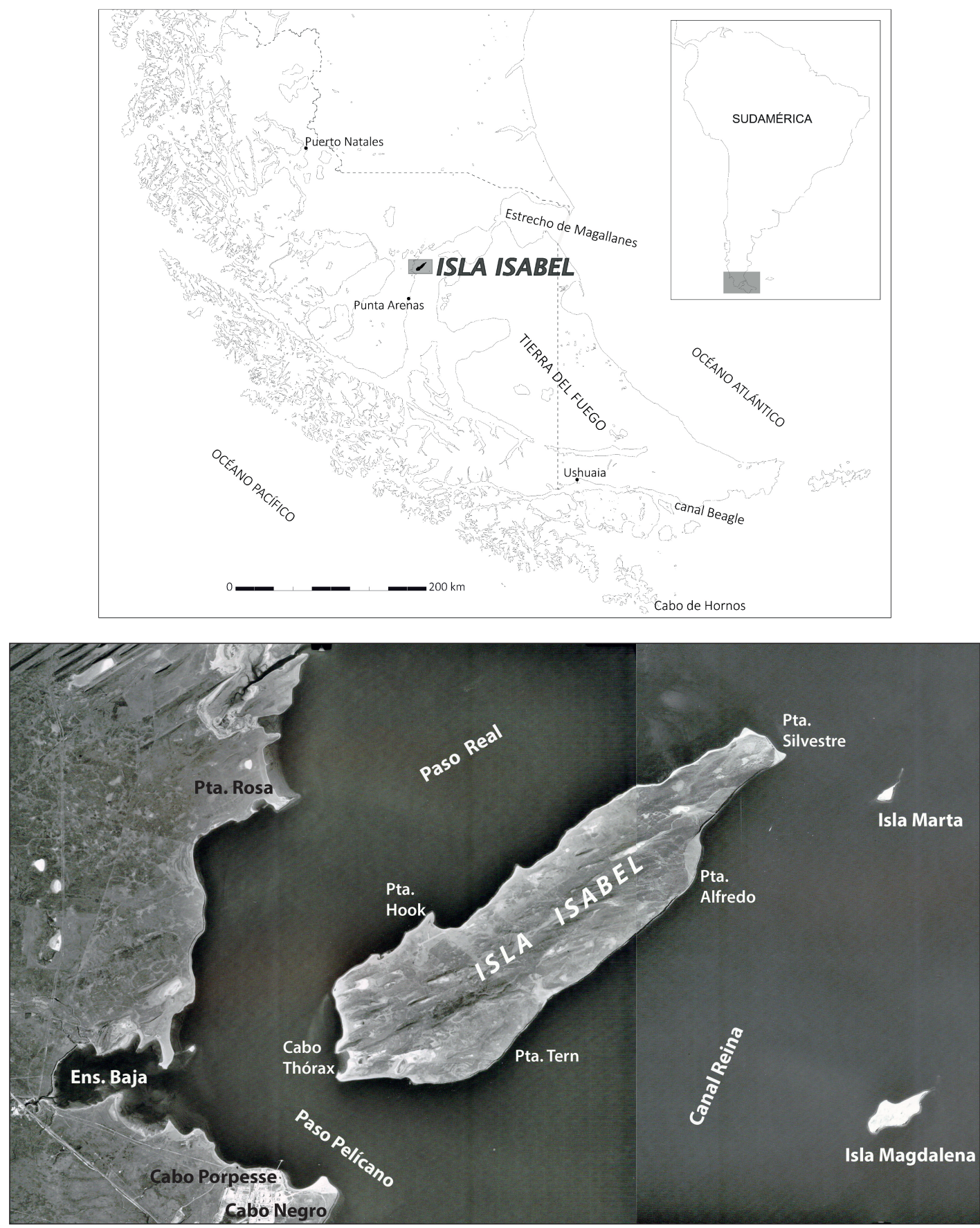

Fig. 1. Localización de isla Isabel.

del siglo XIX. La mayoría de los relatos históricos se limita a consignar la existencia de la isla o a marcar un hito particular en las representaciones cartográficas desde el siglo XVI en adelante. Algunos pocos ofrecen evidencia más útil, que es comparable con la escasa información etnográfica y arqueológica.

Simón de Alcazaba mencionó las islas del centro del Estrecho en enero de 1535, donde realizó cacerías de aves y notó la presencia de 
"indios y Redes de syerbos de venados" (redes hechas con nervios de guanacos, Ortiz Troncoso, 1971 , p. 22), que se usaban para capturar aves en una de estas islas, Magdalena o Isabel (Pastells, 1920).

Hacia el 24 de agosto de 1578 Francis Drake, quien entró al Estrecho por el Este, le dio nombre ${ }^{2}$, Elizabeth Island, en honor a su reina (Martinic, 1992, p. 178; Isla, 2002, p. 39; Coote, 2005 [2003], p. 141). Francis Fletcher, integrante de la misma expedición, presentó una descripción del encuentro con canoeros ocurrido en dicha isla en 1578 (Cooper, 1967[1917], p. 87). Martinic reprodujo el mapa de Fletcher en que figura la isla Isabel (Martinic, 1999, p. 23).

Dumont D'Urville refiere que John Chidley estuvo en Isabel en 1590 y menciona la pérdida de una chalupa con 15 hombres cerca de la isla (Dumont D'Urville, 2011[1841], p. 44), aunque este incidente ocurrió cuando ya Chidley había muerto. La visita fue realizada por los tripulantes del Robin, una de las naves de la expedición de Chidley $^{3}$ (Marley, 2008, pp. 121-122).

El corsario holandés Joris Van Spilbergen observó en 1615 un enterratorio en isla Isabel (Ortiz Troncoso, 1971, p. 23) o isla Magdalena (Cooper, 1967[1917], p. 130) ${ }^{4}$. Se trataba de una choza con "dos cadáveres colocados ... entre arcos clavados en tierra y ramas de haya ... Uno era de talla ordinaria, y el otro no medía más de dos pies y medio. Estaban envueltos en pieles y, en torno al cuello, tenían collares" (Lemaire \& Spilbergen, 1619, en Emperaire, 2002[1958], p. 319). John Narborough, quien también estuvo en la isla en el siglo XVII, mencionó que "Estas gentes son de estatura mediana" (Anónimo, 2007[1711], p. 120). Moseley (1892, p. 480) dice que The island was inhabited at the time of the early Dutch voyages.

La fecha del reconocimiento de la isla Elizabeth de Narborough corresponde al 5 de noviembre de 1670 (Belza, 1978, p. 47; Barros, 1988 , p. 36). Narborough informó que al desembarcar "diecinueve gentes del país bajaron de las colinas" con quienes intercambiaron objetos

2 Cunningham dice que fue "named after the bright occidental star'" (1871).

3 Mateo Martinic escribe John Childley (en Dumont D'Urville, 2011[1841], p. 53). europeos por "arcos, flechas y mantos de pieles, hechos de pieles de crías de guanacos" (Anónimo, 2007[1711], p. 119). Asimismo mencionó la presencia de "grandes perros mestizos" (Anónimo, 2007[1711], p. 122). La descripción realizada los identifica como canoeros, informando que los botes estaban "al otro lado de la isla" (Anónimo, 2007[1711], pp. 121-122). Wood, participante de la misma expedición, comentó que los locales tenían arcos y flechas y llevaban capas de piel de guanaco "que debían probablemente cazar en las pampas continentales vecinas" (Emperaire, 2002[1958], pp. 180, 244).

Más importante aún, también Narborough ubicó en un mapa varios individuos, entre ellos uno con una extraña pieza alrededor del cuello (ver Martinic, 1999, pp. 58-59; Anónimo, 2007[1711]). Dado que sus descripciones etnográficas más detalladas corresponden a la isla Isabel, puede pensarse que estos dibujos resultaron de aquella experiencia. Para el siglo XIX Bove presentó un dibujo, denominado "Una fiesta fueguina", en el que se observan varios nativos llevando un "collar" de carne de ballena, destacando la presencia de una ballena varada en el fondo (Bove, 2005[1883], p. 142, ver también Lefèvre et al. 2003, p. 113). La evidencia de Narborough puede significar, entonces, la explotación de un cetáceo en el estrecho de Magallanes, quizá en la isla Isabel. Recientemente Daniel Quiroz et al. (2016) mostraron la importancia de un grabado de J. B. Zwecker ilustrando una actividad Kawésqar de traslado de trozos de carne de ballena a manera de "poncho", que se reimprimió reiteradamente con variantes, quizá siendo la más famosa la reproducción de Bove (2005 [1883]).

Además, debe recordarse que en un documento de la época de Narborough presentado al rey Carlos II de Inglaterra, se recomienda tomar posesión de la isla Isabel, "dadas sus ventajas naturales" (Barros, 1988; Martinic, 1992, p. 239) y que hasta pudo existir un acto jurisdiccional allî (Martinic, 1992, p. 241). Efectivamente, en uno de sus mapas "aparece dibujada una bandera con la cruz de San Jorge, el conocido pabellón inglés" (Barros, 1988, p. 47).

4 Mateo Martinic (2012) ha presentado una sintesis y discusión de la localización geográfica de las observaciones de los viajeros holandeses en el estrecho de Magallanes. 
En 1690 el Wellfare a cargo de John Strong recaló en isla Isabel y el cirujano George Handisyd colectó plantas que, tras ser donadas a Sir Hans Sloane, fueron la base del herbario fundacional del Museo Británico (Martinic, 1992, p. 237). La lista de plantas colectadas figura en el octavo volumen del listado del herbario Sloane (Godley, 1965, p. 141).

El relato de Bulkeley y Cummins, del viaje de retorno de algunos de los náufragos de H.M.S. Wager, en el Speedwell, informa que desembarcaron gente en Elizabeth Island en diciembre de 1741 buscando, "mucha leña y agua", pero "no encontraron nada", sólo cormoranes y gaviotas (Bulkeley \& Cummins, 2014 [1743], p. 135) o, en otra traducción, gaviotas y pingüinos (Broussain, 2012, p. 168).

Se ha sostenido en una versión anónima publicada en 1767, que en 1764-1765 durante la expedición de H.M.S. Dolphin hubo encuentros entre nativos y Byron en la isla Isabel, los que no figuran en el relato de este navegante (publicado por Hawkesworth en 1773, Cooper, 1967[1917], p. 133). Lipschutz (1950) mostró que en realidad todo lo que se ha hecho en dicha versión anónima es transcribir las observaciones de 1670 de Narborough. Ningún tripulante de H.M.S. Dolphin bajó a isla Isabel, sólo vieron allí canoeros que se acercaron al barco, pero no interactuaron con ellos.

En diciembre de 1767 llegó L.A. de Bouganville, quien al igual que otros la refirió como Isla Santa Isabel (Rolfo \& Ardrizzi, 2007, p. 439)5 5 Entre los que exploraron la isla se encuentra el naturalista Philibert Commerson (Godley, 1965, p. 142). Bouganville mencionó que "Es posible que los salvajes vengan a esta isla. Hemos encontrado un perro muerto, huellas de una fogata y restos de comida a base de conchas" (Bouganville, 2005[1772], p. 174). Más allá de eso informó sobre la ausencia de madera en la isla.

En la expedición comandada por Philip Parker King, H.M.S. Beagle visitó la isla en los años 1826-1827 (ca. 31/12/1826-3/1/1827) $)^{6}$.

5 También ver Dumont D'Urville (2011[1841], p. 39) o Spry (1876, p. 362).

6 Entre muchos otros casos, particularmente durante las expediciones hidrográficas inglesas de los años 1820 y 1830, fueron destacadas las capacidades de la isla Isabel como fondeadero (Parker King, 1831). Esto también
Los marinos ingleses estaban acompañados por tres indígenas-intérpretes abordados en San Gregorio, quienes llaman Turretterr a la isla Isabel (ver Fitz Roy, 2009[1839], p. 51). Estos individuos son interpretados como "alacalufes" por Poletti Formosa (1979), pero son claramente cazadores terrestres. La nave ancló inicialmente al NE de la isla, pero luego ubicó un "buen fondeadero, sin corriente, al norte de la isla" (Parker King en Fitz Roy, 2009[1839], p. 51, Bitácora de H.M.S. Beagle, depositada en el Public Record Office de Londres). Parker King la visita en el bote Hope en 1826 y menciona haber visto restos de wigwams y acumulaciones de conchas (en Fitz Roy, 2009[1839], p. 105). Desde allí observaron fuegos en los alrededores de Cabo Negro, hechos por los "Patagones" que esperaban a sus tres compañeros (MacDouall, 1833, pp. 8283). El Capitán Low informó a Fitz Roy haber visto canoeros en 1834 en isla Elizabeth (Fitz Roy, 1839, p. 173). Fitz Roy retornó a la isla a cargo de la Beagle en ese mismo año. Hay por lo menos un dibujo de Martens realizado durante esa visita de 1834. Se trata de una Caryophyllia sp. ${ }^{7}$. Martens menciona sucesivas visitas a la isla el 31 de enero y el 12 de febrero de 1834 (Organ, 1994, pp. 23-24). Darwin colectó once especies de plantas en la isla (Godley, 1965, p. 163). En su correspondencia se encuentra una carta dirigida a J.D. Hooker, escrita en Down House el 10 de diciembre de 1845, en la que le comenta I think you ought somewhere to explain where C. Negro \& Elizabeth island are, as few would be able to find out without the best charts (Darwin, C., Correspondence Database, http:// www.darwinproject.ac.uk/entry-935, visitado 28 de julio de 2012) ${ }^{8}$.

Darwin, quien se encontraba a bordo durante las visitas de 1834, escribió el 12 de febrero que During the day we passed close to Elizabeth Island, on North end of which there was a party of Fuegians with their canoe\&c (sic). They were tall men \& clothed in mantles; belong probably

ocurre, por ejemplo, en los viajes de la fragata Santa María de la Cabeza en 1785-1786 (Vargas de Ponce, 1788, pp. 31, 107).

7 http://www.lib.cam.ac.uk/ConradMartens/fulldisplay. php?record $=41$

8 Ver Burkhardt y Smith (1988). 
to the East Coast; the same set of men we saw in Good Success Bay; they clearly are different from the Fuegians \& ought to be called foot Patagonians (Darwin, 1988, p. 221). Esta es una referencia a la presencia de individuos de afiliación tanto terrestre como marítima en la isla.

En 1846 un grupo de misioneros rumbo a Oceanía se detuvo en la isla. P. Meriais escribió que algunos miembros del grupo bajaron a la isla y estuvieron alli demorados por una tormenta, período durante el cual construyeron una cruz de pino de más de tres metros de alto (Meriais, 1847, p. 379). Debe decirse que esta historia de campamentos transitorios muchas veces asociados con construcciones más o menos obstrusivas de viajeros y navegantes, seguramente debió comenzar antes de esta fecha -por ejemplo la cruz erigida por los tripulantes de la goleta Ancud en el sector más alto de la isla en 1843 (Anrique, 1901, p. 49)-, y sin dudas continuó como lo prueban los desechos de cortas estadías marcados por botellas y otros restos identificados por Bird en la década de 1930 (1980, p. 83). A fines de la década de 1860 Robert Oliver Cunningham dejó algunos de sus tripulantes acampando en la isla durante varios días para cazar aves (Cunningham, 1871, pp. 136, 153, 266).

Jean Louis Agassiz visitó isla Isabel en el buque hidrográfico Hassler, bajo el comando de Philip Carrigan Johnson, en el año 1872 y realizó observaciones geológicas (Agassiz, 1872) y zoológicas (Agassiz, 1888). El viaje de Agassiz, el más importante representante del creacionismo a fines del siglo XIX repitió, en alguna medida, la visita a algunos de los lugares importantes en el recorrido de Darwin, tales como el estrecho de Magallanes y las islas Galápagos (Gould, 1984).

La visita de H.M.S. Rocket a cargo de Sir Rose Lambart Price ocurrió en enero de 1875 (Lambart Price, 1877). En 1876 se realizó, como ya veremos, la visita de H.M.S. Challenger. Enrique Ibar Sierra (2002[1877], p. 62) visitó la isla en octubre de 1877 a bordo de la corbeta Magallanes, en la que desarrolló un programa de muestreo de moluscos y flora acuática. Francisco P. Moreno comentó su paso por tierra frente a la isla Isabel en el otoño de 1877 (1969[1879], p. 404) para, dos páginas más adelante, presentar una lista de etnías meridionales en la que incluye a los Elisalá'as (ib. p. 406). Cooper se pregunta si se refiere a los Elizabeth Islanders (1967[1917], p. 113).

En enero de 1879 pasó Richard William Coppinger, quien se desempeñaba como cirujano del crucero Alert (Coppinger, 2007[1883]). Este crucero se ocupó del traslado de caballos a la isla, oportunidad que aprovechó Coppinger para realizar numerosas observaciones naturalistas.

En noviembre-diciembre de 1897 pasó por la isla una expedición multinacional en el Belgica (Arctowski, 1901; Cook, 1998[1900]). Entre muchos otros, en esta última expedición participaron los notables exploradores polares Frederick A. Cook, Adrien de Gerlache de Gomery y Roald Amundsen, así como el naturalista rumano Emile-Georges Racovitza (Yelverton, 2004; Racovitza, 1998).

Ya en el siglo XX, hay que destacar que el 18 de noviembre de 1928 se realizó un "trial trip" a las islas Isabel y Marta por parte de miembros de la expedición finesa a la Patagonia. En esa oportunidad filmaron aves y mamíferos marinos en las islas (Auer, 1934, p. 8).

Como esta información claramente demuestra, la situación central en el estrecho de Magallanes le ha conferido a la isla un importante papel dentro del sistema de circulación de naves occidentales a partir del siglo XVI. Por esa razón la isla Isabel tiene amplia representación en la cartografía magallánica (Martinic, 1999). Los escasos antecedentes etnográficos y arqueológicos muestran que la isla también asumió un lugar importante dentro de la geografía cultural prehistórica.

\section{ARQUEOLOGÍA}

\section{Desarrollos Históricos}

En el año 1999, como parte de un proyecto mayor (Borrero, 1998), se estudiaron los materiales arqueológicos depositados en el British Museum. Entre ellos se incluyeron los escasos restos líticos recolectados el 19 de enero de 1876 en la Isla Isabel, por miembros de la expedición de H.M.S. Challenger (Borrero \& Franco, 2001). Los materiales fueron donados al Museo por Moseley en 1877 y por Thomson y Moseley en 1878, e incluyen una punta de proyectil lítica (número de 
registro $\mathrm{AM}+.473$ ) y lascas de obsidiana negra (AM +.474 b y $\mathrm{AM}+.474 \mathrm{a}$ ). Estos escasos materiales resultaron de una excavación en la isla que hallaron llena de "middens of large extent, which are full of vast quantities of bones of Otaria jubata" (Moseley, 1892, pp. 479-480; también Linklatter, 1974 , p. 264). Esta fue una de las primeras excavaciones realizadas en Patagonia, cumplida durante la corta permanencia de dos días de esta nave (Thompson \& Murray, 1895, p. 1167). Mr. Murray estuvo a cargo de las excavaciones and found some stone arrow-heads and stone fishing-net sinkers (Moseley, 1892, p. 480). Se ha descripto la presencia de ... bones of Guanacos, of a small Rodent, of Fur Seals, Whales, Porpoises, Penguins, Rheas, Terns, and Shags. Some of the bones were charred, some were split, and some fashioned into awls and needles (Tizzard et al. 1885 , p. 872). Moseley destaca que además de esos middens, there are plenty of small shallow circular excavations with the thrown-out earth heaped around, which mark the site of Fuegian huts (ib.). Existen algunas fotografías e ilustraciones tomadas durante esa expedición (Brunton, 1994: Photos No. 604, 605, 606).

En años posteriores la isla siguió atrayendo intereses arqueológicos. Domenico Lovisato visitó la isla en 1882 (Lovisato, 1884) y como resultado publicó una descripción de los conchales que encontró allí expuestos. Se debe destacar la presencia de "vidrio volcánico estallado" (en Bird, 1980, p. 77). En enero de 1888 el Albatross, barco del Bureau of Fisheries de USA, recaló en la isla y algunos de sus miembros realizaron excavaciones. En relación a ese viaje Townsend describió la presencia de kitchen middens ... several feet thick y habló del hallazgo de A few arrow-heads, bone, flint and stone implements with bones of seals (Townsend, 1910, p. 14). Townsend publicó una foto con el epígrafe Exploring an ancient shell heap. Elizabeth Island, Straits of Magellan (Townsend, 1910, p. 16) (Fig. 2) ${ }^{9}$. Como ya dijimos, hacia $1897 \mathrm{el}$ Bélgica visitó la isla y colectó a number of flint arrows and spear points .... in the numerous

9 La foto se aprecia en http://www.photolib.noaa.gov/ htmls/fish7827.htm. "Kitchen midden at Elizabeth Island, Strait of Magellan as excavated by the Albatross party with the Albatross at anchor, 1888. Fish7827, NOAA's heaps of mussel shells and other sites of old Indian encampments (Cook, 1998[1900], p. 78). Ya en el siglo XX, Junius Bird realizó trabajos arqueológicos en la isla en 1935-1936, publicando una lista de 38 sitios (Bird, 1980). El 17 de febrero de 1937 Bird registró los sitios desde el aire, al sobrevolar la isla con Franco Bianco (Martinic, 1984). El catálogo de los materiales recolectados, depositados en el American Museum of Natural History (AMNH, Catalog 41.1), incluye las entradas 2510-2626 (ver listado en Bird, 1980, pp. 86-87). Ortiz Troncoso publicó fotografías de dos perforadores líticos, 11 instrumentos líticos y tres cuñas óseas obtenidas por Bird en la isla (Ortiz Troncoso, 1984, pp. 119-120). Finalmente Omar Ortiz Troncoso visitó la isla en 1968, descubriendo varios sitios que incluyen un enterratorio, varias estructuras monticulares $y$ materiales en superficie en sectores erosionados (Ortiz Troncoso, 1971).

\section{Nuevas Investigaciones}

La recopilación de información histórica, etnográfica y arqueológica permitió relacionar los depósitos arqueológicos con los descritos por distintos viajeros. Los cambios en los depósitos arqueológicos fueron comparados entre las sucesivas campañas de terreno atendiendo a las características de sus depósitos arqueológicos (Bird, 1938, p. 259) y bajo la óptica de isla Isabel como punto de inflexión en la distribución o límite oriental de las poblaciones canoeras. A esto se sumaba su condición de bisagra y apertura desde la estepa hacia las franjas fitogeográficas de bosque, zona precordillerana y archipiélago fueguino (p.e. Pisano, 1977), otorgándole importante significado en términos de biogeografía humana a los resultados alli obtenidos.

El límite de la distribución de los grupos prehistóricos especializados en ambientes marinos ha sido visto por algunos autores como relacionado con la distribución del bosque (Orquera et al. 2006, p. 286), el que hoy no se observa en la isla (ver Ibar Sierra, 2002[1877], p. 62; Bird, 1980, p. 76).

Historic Fisheries Collection, Archival Photographer Stefan Claesson (Gulf of Maine Cod Project, NOAA National Marine Sanctuaries; Courtesy of National Archives)". 


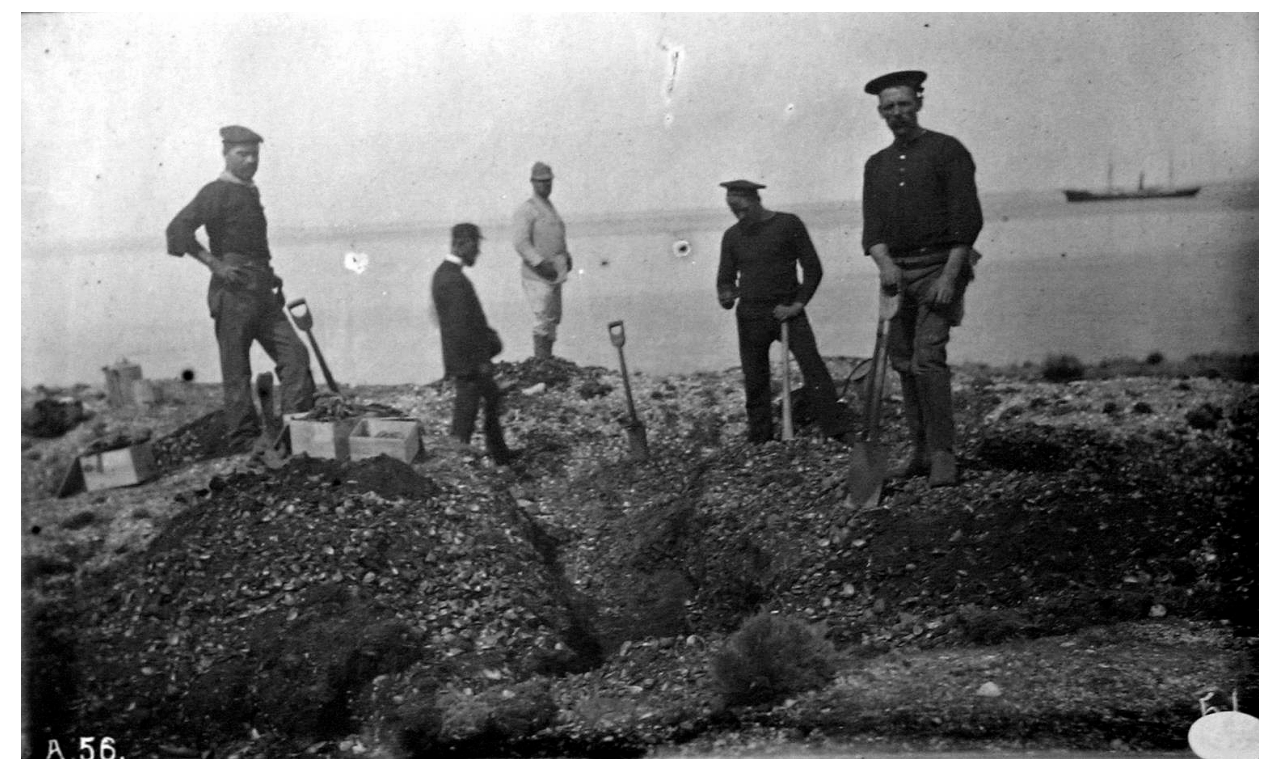

Fig. 2. Fotografía de la excavación de Townsend.

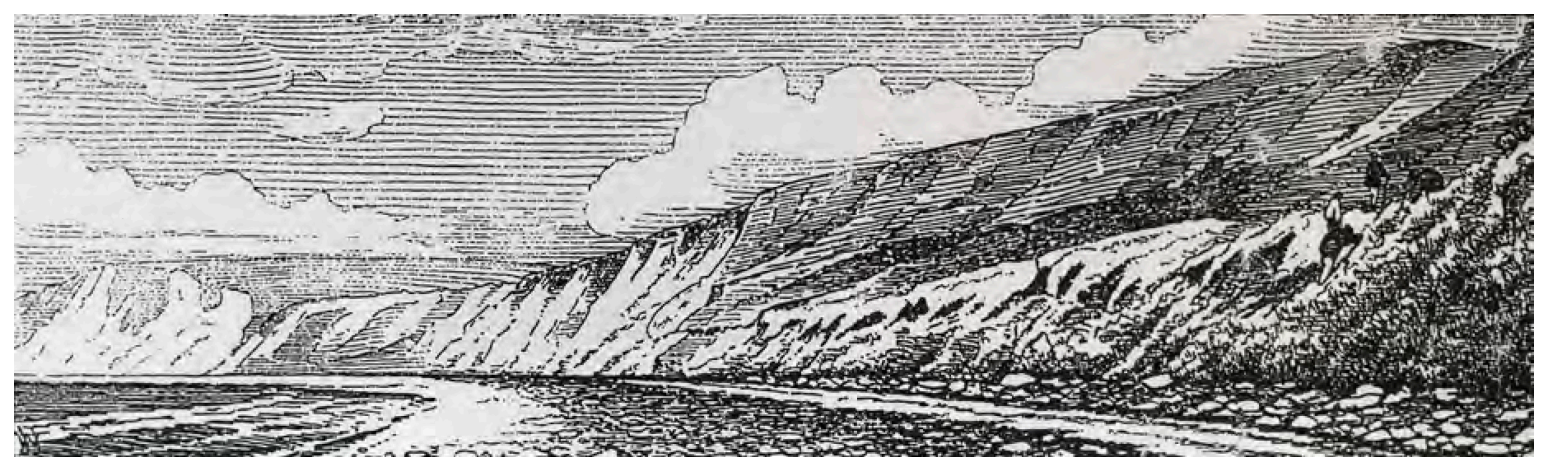

Figs. 3 y 4 . Dibujos de Wild.

Sin embargo alrededor de 1876 Meade observó que la isla Isabel era el lugar where trees first make their appearance (Meade, 1897, p. 132). Esta última es una referencia demasiado general como para discutir el seguro carácter estepario de la isla y quizá referible a las observaciones de árboles a partir de Cabo Negro y desde allí hacia el occidente (Parker King, 1831, p. 167; MacDouall, 1833, p. 83). Hay que recordar, por otra parte, que hubo tala de árboles en el área de bahía Laredo-Cabo Negro desde el siglo XIX (Santana et al. 2001, p. 56). La ausencia de árboles en la isla notada por Moseley en 1876 (Moseley, 1892, p. 479), por Ibar Sierra

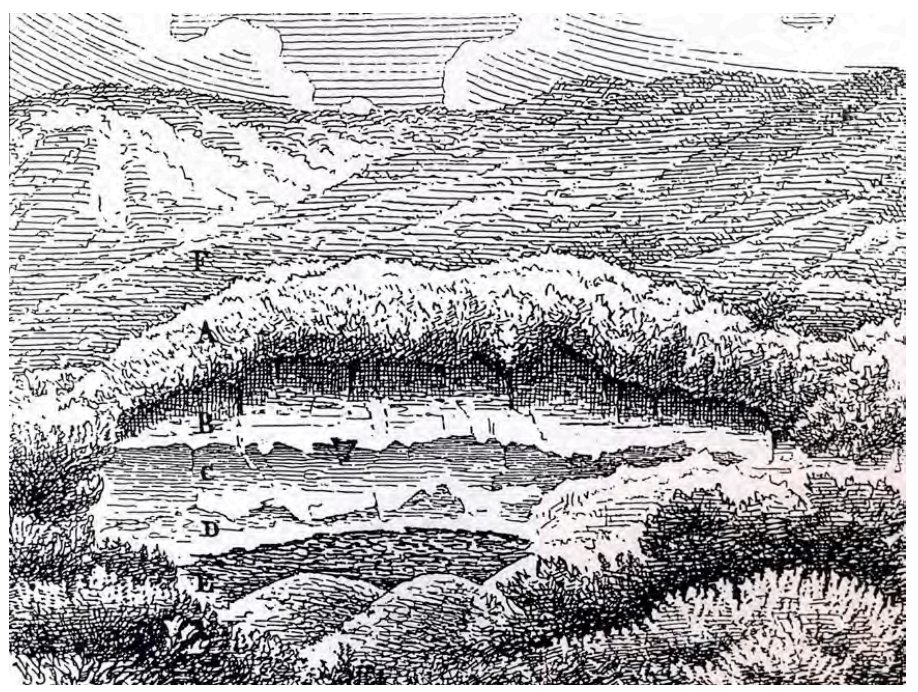


en 1877 (2002[1877], p. 62) y por Philippi en 1843 (Anrique, 1901, p. 49) parece determinante para suponer una situación similar a la actual en el pasado.

El trabajo arqueológico incluyó una extensa prospección concentrada en la línea costera y algunas transectas interiores. Además se realizaron excavaciones de sondeo y barreno en algunos sitios seleccionados por su relación con relatos históricos o rasgos particulares, utilizándose viejas fotografías y dibujos como referencias (Figs. 2, 3 y 4). Las campañas de terreno se desarrollaron en mayo del año 2001, 18-31 de enero de 2002 y el 1-10 de marzo de 2003.

La metodología básica consideró transectas y -dada la escasa visibilidad en superficie debido a la cubierta vegetal- la unidad de análisis fue el sitio. Se realizaron sondeos en cuatro sitios y en muchos casos se completó la evaluación de los depósitos con pruebas de barreno. En todos los sondeos se recogieron muestras de moluscos en forma sistemática, para su estudio detallado. Además, en Cabo Thórax se realizaron observaciones distribucionales a lo largo de una transecta perpendicular a la costa que sirvió para destacar la continuidad del registro arqueológico a lo largo de por lo menos 180 metros y un sistema de dos niveles aterrazados (ver Di Grande et al. 1996). Se detectó la presencia de sitios deflacionados en varios sectores del interior, al menos uno de los cuales es interpretable como un taller lítico. Además de la información arqueológica, se recuperó información tafonómica, que permitió evaluar variaciones en el potencial de enterramiento y preservación del registro fósil.

La prospección de la línea de costa incluyó toda la periferia de la isla, generándose un catálogo de sitios que fueron comparados con los datos del survey de Bird de 1935 y 1936 (Bird, 1980). Cuando resultó posible, se estableció una equivalencia entre sus datos y los nuestros (Tabla 1, Fig. 5). Se registraron 28 de los sitios descritos

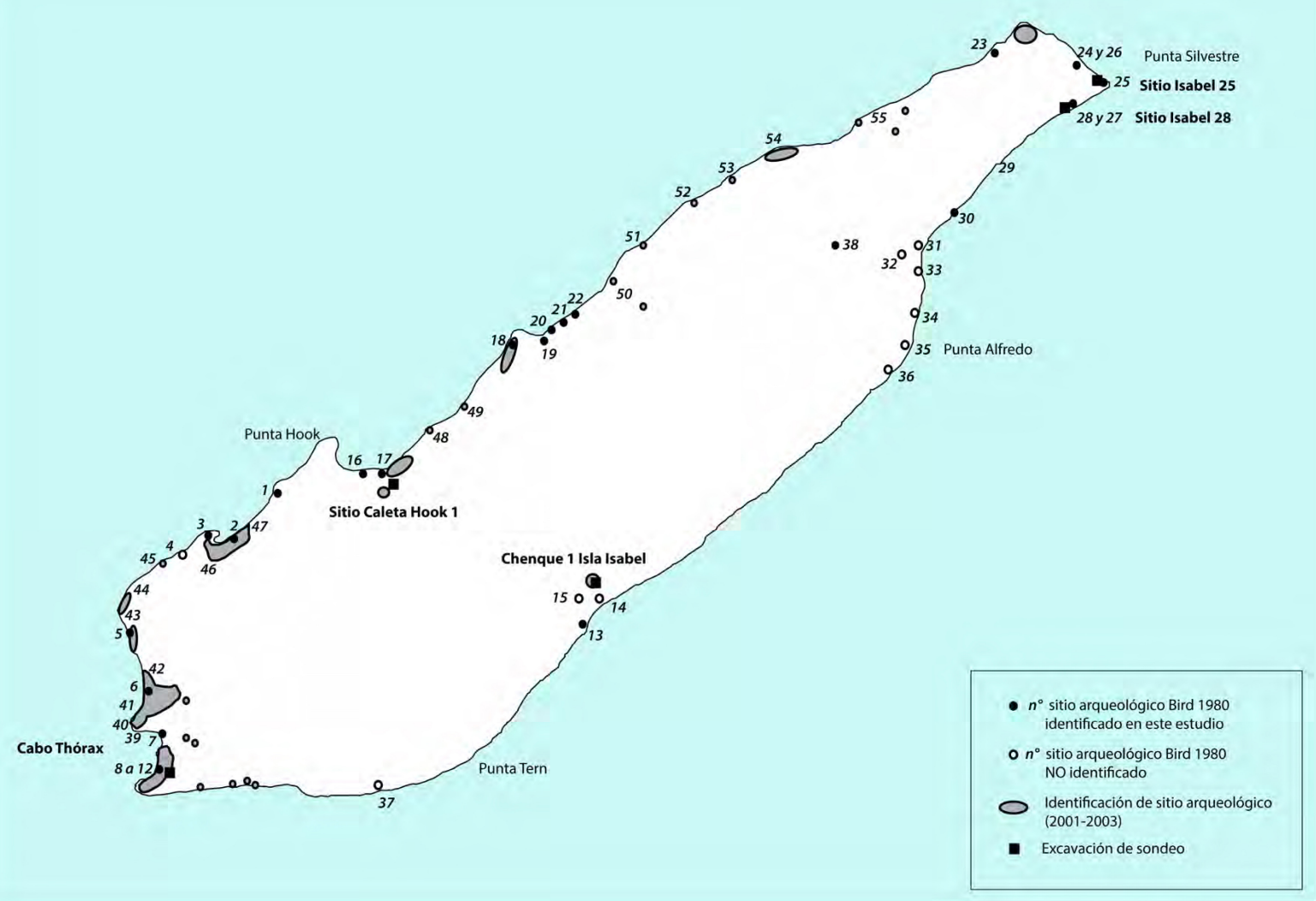

Fig. 5. Mapa de distribución de sitios ubicados por Bird (1980) y por nosotros. 
previamente por Junius Bird (1980), otros 10 resultaron dudosos de identificar y al menos 18 nuevos loci de registro arqueológico pueden considerarse hallazgos nuevos. Efectivamente, se ubicaron varios yacimientos que no habían sido registrados por Bird, muchos de ellos en posiciones relativamente alejadas de la línea de costa, que probablemente fue el espacio mayormente explorado por ese investigador.

Como conclusión de esta tarea resultó claro que muchos de los sitios indicados por Bird aún eran identificables como unidades relativamente discretas a comienzos del siglo XXI. Otros sitios, en particular en Cabo Thórax (por ejemplo \#12, \#8), parecen haber perdido identidad, quizá como resultado de procesos postdepositacionales (ver otros casos en Tabla 1 y Fig. 3). La remoción de la cubierta vegetal por erosión pudo haber revelado un registro que no estuvo visible para Bird, o pudo precipitar procesos de dispersión que produjeron mezclas entre las unidades reconocidas en 1935-1936 (Borrero, 2004). De todas maneras, en la mayoría de los casos la identificación se ve muy facilitada por su relación con rasgos geográficos, además de por la buena descripción realizada por Bird.

Por ejemplo, identificamos un conchal correspondiente al sitio \#23. Tanto la ubicación general como la situación específica junto a un chorrillo permiten sostener esta interpretación. La única importante diferencia observada es que la extensión del sitio es mucho mayor que la descrita por Bird. Nuevamente la remoción de la cubierta vegetal puede ser la explicación. Se observó un depósito de varios decímetros de espesor, bajo el cual aflora la arcilla. Al momento de nuestra visita se observaban en el perfil un cráneo de delfín, huesos de lobo y de guanaco, además de abundantes huesos de ave, incluyendo pingüino. Se recuperó un peroné humano en superficie. También detectamos la presencia de dos fragmentos de obsidiana verde cerca del sitio \#23 de Bird (1980, p. 84).

\section{Sitio Isabel 28}

En el recorrido por la playa entre las localizaciones \#27 y \#28 de Bird se registró un conchal. Se ubica en el sector que había sido identificado por Lovisato y sondeado por los tripulantes de la Challenger, los que interpretamos que se refieren al mismo sitio. Nuestra identificación se basa en la comparación con la lámina de John James Wild ${ }^{10}$ publicada (Spry, 1876; Moseley, 1892; Thompson \& Murray, 1895) y la foto \#605 publicada por Brunton (1994), a la vez identificable al menos en parte con el sitio \#28 de Bird. Se sondeó allí, cerca del borde de la barranca, en un sector con pendiente marcada (unidad de 50 × $50 \mathrm{~cm}$ ). Se trata de un conchal de un espesor de unos $20-25 \mathrm{~cm}$, que llega hasta unos $40 \mathrm{~cm}$ por debajo de la superficie. Los primeros $10 \mathrm{~cm}$, básicamente arena suelta con raicillas, incluyen excrementos de oveja, pero a partir de allí no hay registro de ese animal. A partir de los $20 \mathrm{~cm}$ el sedimento es areno-limoso con pequeños guijarros. La mayor densidad de registro arqueológico se encuentra entre los 30-40 cm de profundidad. El conchal está constituido por valvas de mauchos, choritos y almejas. Dos huesos de ave en posición articulada y tres costillas y una tibia de lobo marino en posición horizontal hablan de relativa estabilidad de los materiales. Se recuperaron dos percutores líticos (uno del tipo en arista de cuarcita y otro con trituramiento acotado en un extremo de punto, materia indeterminada), una preforma de bola fracturada confeccionada sobre gabro y dos lascas internas (andesita y roca silícea).

Entre los hallazgos de materiales óseos del sitio Isabel 28 se identificaron huesos de guanaco, lobo marino, ave -incluyendo pingüino-, cánido y pez a lo largo de un extenso perfil. La tibia de Otaria flavescens recuperada a $50 \mathrm{~cm}$ de profundidad fue fechada en $2.545 \pm 45 \mathrm{AP}, \mathrm{d}^{13} \mathrm{C}-10.5$ (Ua-21036), aunque debe considerarse un efecto reservorio de 550 años similar al de Mytilus sp. y Nacella sp. (cf. San Román et al. 2009). Como dijimos, este sitio probablemente también corresponda al observado por Lovisato, quien habla de su ubicación sobre el lado del paso Real, llegando al extremo de la isla, lo que es concordante. En las colecciones de Bird, depositadas en el American Museum of Natural History, el material correspondiente al sitio \#28 está entrado como "Lovisato's Midden, Layers A, $B, C$ ". Bird comentó a su esposa Margaret que allî no vio nada parecido a los "huge middens" descritos 
Tabla 1. Inventario de sitios arqueológicos y características registradas por Bird (1980) y en el presente estudio.

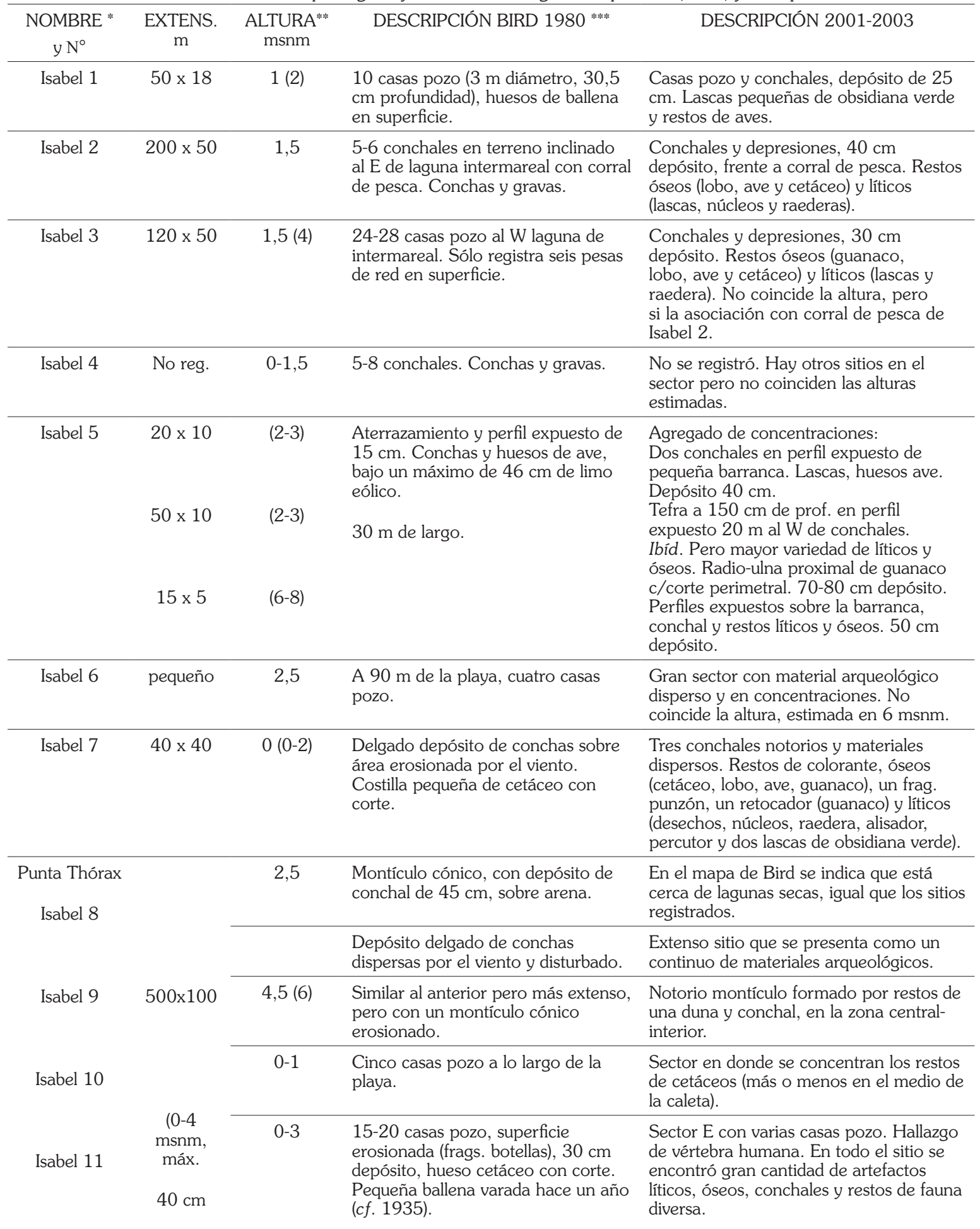

Isabel 12 Depósito) 


\begin{tabular}{|c|c|c|c|c|}
\hline $\begin{array}{l}\text { NOMBRE* } \\
y \mathrm{~N}^{\circ}\end{array}$ & $\begin{array}{l}\text { EXTENS. } \\
\mathrm{m}\end{array}$ & $\begin{array}{l}\text { ALTURA }^{* * *} \\
\text { msnm }\end{array}$ & DESCRIPCIÓN BIRD 1980 **** & DESCRIPCIÓN 2001-2003 \\
\hline Isabel 13 & & $1-3,7$ & $\begin{array}{l}40 \text { casas pozo, al E barranco } \\
\text { abrupto de } 10 \mathrm{msnm} \text {. }\end{array}$ & Sitios cercanos al Chenque 1 Isabel. \\
\hline Isabel 14 & & 0 & $\begin{array}{l}2-5 \text { casas pozo, erosionado por el } \\
\text { mar. }\end{array}$ & \\
\hline Isabel 15 & reducido & 4,5 & $\begin{array}{l}\text { Extensión con conchas, apegadas a } \\
\text { un declive a } 270 \mathrm{~m} \text { de la playa. }\end{array}$ & \\
\hline Isabel 16 & $40 \times 20$ & $\begin{array}{l}0-2,5 \\
(3-4)\end{array}$ & $\begin{array}{l}\text { Conchal de } 45 \mathrm{~cm} \text { espesor que } \\
\text { forma parte del sitio } 17 \text {, área } \\
\text { erosionada por viento. }\end{array}$ & $\begin{array}{l}\text { En Caleta Hook, frente a las casas de la } \\
\text { estancia. Conchales y pozos erosionados } \\
\text { (difusos). Materiales líticos y óseos } \\
\text { diversos. }\end{array}$ \\
\hline Isabel 17 & $400 \times 30$ & (2) & $\begin{array}{l}\text { El más extenso de la isla: } 30 \\
\text { x } 18 \mathrm{~m} \text {, con } 90 \mathrm{~cm} \text { espesor, y } \\
\text { asociado a extenso depósito poco } \\
\text { profundo de } 200 \times 6 \text { m erosionado. } \\
\text { Se registraron restos humanos } \\
\text { en superficie, restos de fauna y } \\
\text { conchas. }\end{array}$ & $\begin{array}{l}\text { En Caleta Hook, frente a las casas de } \\
\text { la estancia. Conchales erosionados } \\
\text { y dispersos, depósito máx. } 50 \mathrm{~cm} \text {. } \\
\text { Diversidad de restos líticos y óseos } \\
\text { (obsidiana verde, cuña ósea). }\end{array}$ \\
\hline Isabel 18 & $400 \times 10$ & (5) & $\begin{array}{l}\text { Al borde de barranca de } 3 \mathrm{~m} \text { cerca } \\
\text { de la playa, conchas y líticos. }\end{array}$ & $\begin{array}{l}\text { Extenso conchal en perfil expuesto sobre } \\
\text { terraza. Depósito } 60 \mathrm{~cm} \text {. Diversidad de } \\
\text { materiales, costillas cetáceo cortadas, } \\
\text { guanaco (corte perimetral) y fémur } \\
\text { humano, entre otros restos líticos y óseos. }\end{array}$ \\
\hline Isabel 19 & $30 \times 5$ & $\begin{array}{l}0-1,5 \\
(1-2)\end{array}$ & 13 casas pozo, pocos desechos. & $\begin{array}{l}\text { Conchal expuesto en perfil. Material lítico } \\
\text { y óseo. }\end{array}$ \\
\hline Isabel 20 & $50 \times 10$ & $0-1,2(2)$ & $\begin{array}{l}13 \text { casas pozo, pocos desechos. } \\
\text { Planta ovalada versus circular que es } \\
\text { lo común. }\end{array}$ & $\begin{array}{l}\text { Conchales y depresiones parcialmente } \\
\text { erosionadas. Material lítico y óseo. A } 20 \\
\text { m del sitio Isabel } 21 \text {. }\end{array}$ \\
\hline Isabel 21 & $100 \times 20$ & $(2-4)$ & $\begin{array}{l}11 \text { conchales, en aterrazamiento } \\
\text { bajo barranca y cerca de su borde. } \\
\text { Pocos desechos. }\end{array}$ & $\begin{array}{l}\text { Dos líneas de conchales, una cerca de la } \\
\text { pleamar y otra a los pies del barranco. } 30 \\
\text { cm depósito. Material lítico y óseo. }\end{array}$ \\
\hline Isabel 22 & $15 \times 15$ & $1,8(4)$ & Ocho conchales, pocos desechos. & $\begin{array}{l}\text { Similar al sitio Isabel 21. Material lítico } \\
\text { y óseo. }\end{array}$ \\
\hline Isabel 23 & No reg. & No reg. & $\begin{array}{l}\text { Pequeño depósito de conchas junto } \\
\text { a un arroyo, erosionado. }\end{array}$ & $\begin{array}{l}\text { Gran perfil expuesto, junto a la playa. } \\
\text { Se visitó durante el año } 2000 \text { y también } \\
\text { en el } 2001 \text { y } 2003 \text {. Recolección de } \\
\text { fíbula humana. En el perfil se observa un } \\
\text { cráneo de delfín. }\end{array}$ \\
\hline Isabel 24 & No reg. & 5 & $\begin{array}{l}\text { Ocho conchales en terraza alta junto } \\
\text { a barranca alta. Conchas y líticos en } \\
\text { superficie. }\end{array}$ & Terraza alta. \\
\hline Isabel 25 & No reg. & $0-1,5$ & $\begin{array}{l}15 \text { casas pozo (circulares, } 3,6 \mathrm{~m} \\
\text { diámetro, } 20 \mathrm{~cm} \text { de conchas). }\end{array}$ & $\begin{array}{l}\text { Terraza baja. Trinchera de sondeo en } \\
\text { casa pozo. }\end{array}$ \\
\hline Isabel 26 & No reg. & No reg. & $\begin{array}{l}\text { Conchas en antigua siembra } \\
\text { de papas, zona uniformemente } \\
\text { inclinada }\end{array}$ & \\
\hline Isabel 27 & No reg. & 3 & $\begin{array}{l}\text { Lo toma como parte del conchal } \\
\text { Lovisato. Sector erosionado, un } \\
\text { poco más arriba de la playa observó } \\
\text { huesos y líticos en superficie. }\end{array}$ & $\begin{array}{l}\text { Sector con dunas, erosionado por el } \\
\text { viento hacia el sur de la punta, donde } \\
\text { comienza la barranca. }\end{array}$ \\
\hline
\end{tabular}




\begin{tabular}{|c|c|c|c|c|}
\hline $\begin{array}{l}\text { NOMBRE * } \\
y^{\circ}\end{array}$ & $\begin{array}{l}\text { EXTENS. } \\
\mathrm{m}\end{array}$ & $\begin{array}{l}\text { ALTURA }^{* * *} \\
\text { msnm }\end{array}$ & DESCRIPCIÓN BIRD 1980 **** & DESCRIPCIÓN 2001-2003 \\
\hline Isabel 28 & No reg. & 6 & $\begin{array}{l}1 \text { km más allá de sitio 27. Capas de } \\
\text { conchal y depósitos de derrumbe de } \\
\text { la barranca. Señala grandes cambios } \\
\text { en relación a lo visto por Lovisato. } \\
\text { Trinchera con boleadoras, punzones, } \\
\text { cuña y arpón multidentado. Restos } \\
\text { óseos de lobo marino, aves, } \\
\text { guanaco, cánido y pescado. }\end{array}$ & $\begin{array}{l}\text { Se interpreta como parte del mismo sitio } \\
\text { de Lovisato y la identificación se basa } \\
\text { en las semejanzas con la lámina de John } \\
\text { James Wild. }\end{array}$ \\
\hline Isabel 29 & No reg. & $0-1$ & $\begin{array}{l}\text { Siete conchales, depósito de } 38 \mathrm{~cm} \\
\text { de conchas. Sector plano y bajo, al } \\
\text { pie del barranco. }\end{array}$ & No reg. \\
\hline Isabel 30 & No reg. & No reg. & $\begin{array}{l}\text { Similar a sitio } 29.3 \text { conchales y } 30 \\
\text { cm depósito. }\end{array}$ & No reg. \\
\hline Isabel 31 & No reg. & No reg. & $\begin{array}{l}\text { Conchal de } 90 \mathrm{~cm} \text { espesor, } 20 \text { casas } \\
\text { pozo y conchales, más } 5 \text { en la grava } \\
\text { al frente. Excavación de sondeo de } \\
2 \text { x } 3 \mathrm{~m} \text { aprox. Registra puntas de } \\
\text { lanza. }\end{array}$ & No reg. \\
\hline Isabel 32 & No reg. & No reg. & $\begin{array}{l}\text { Nueve casas pozo dispersas en } \\
\text { planicie al W de manantial. }\end{array}$ & No reg. \\
\hline Isabel 33 & No reg. & No reg. & $\begin{array}{l}16 \text { casas pozo muy dispersas, pocos } \\
\text { desechos. }\end{array}$ & No reg. \\
\hline Isabel 34 & No reg. & No reg. & $\begin{array}{l}15 \text { casas pozo muy dispersas, pocos } \\
\text { desechos. }\end{array}$ & No reg. \\
\hline Isabel 35 & No reg. & No reg. & $\begin{array}{l}\text { Cinco casas pozo muy dispersas, } \\
\text { pocos desechos. }\end{array}$ & No reg. \\
\hline Isabel 36 & No reg. & $>1$ & $\begin{array}{l}\text { Conchal en perfil expuesto en } \\
\text { barranca abrupta. } 38 \mathrm{~cm} \text { tierra y } 20 \\
\mathrm{~cm} \text { conchal, sobre arena y grava. }\end{array}$ & No reg. \\
\hline Isabel 37 & No reg. & No reg. & $\begin{array}{l}\text { Conchal en declive al SW de una } \\
\text { barranca. Líticos, raspadores. }\end{array}$ & No reg. \\
\hline Isabel 38 & pequeño & No reg. & $\begin{array}{l}\text { Interior isla, al final de pequeña } \\
\text { laguna. } 15 \mathrm{~cm} \text { de conchas y huesos } \\
\text { de ave. }\end{array}$ & Bolas en superficie. \\
\hline \multirow[t]{2}{*}{$\begin{array}{l}\text { Chenque } 2 \\
\text { isla Isabel }\end{array}$} & $15 \times 10$ & No reg. & No reg. & Dos estructuras de piedra semicirculares. \\
\hline & & & Cercano a los sitios 16 y 17 . & Descubierto en marzo del 2003. \\
\hline $\begin{array}{l}\text { Caleta } \\
\text { Hook } 1\end{array}$ & No reg. & $(>20)$ & & $\begin{array}{l}\text { Conchales y depresiones con una } \\
\text { cubierta de pasto homogénea. Se } \\
\text { desarrollaron sondeos de barreno y un } \\
\text { pozo. }\end{array}$ \\
\hline Isabel 39 & $15 \times 5$ & $(1-3)$ & No reg. & $\begin{array}{l}\text { Cuatro conchales. } 20-30 \mathrm{~cm} \text { depósito. } \\
\text { Restos de aves y lobo. Lascas. }\end{array}$ \\
\hline Isabel 40 & $8 \times 2$ & (1) & No reg. & $\begin{array}{l}\text { Pequeño conchal en perfil expuesto } \\
\text { por la playa actual. con } 30 \text { a } 40 \mathrm{~cm} \text { de } \\
\text { depósito. }\end{array}$ \\
\hline Isabel 41 & $8 \times 2$ & (1) & No reg. & $\begin{array}{l}\text { Igual a Isabel } 40 \text { pero con más potencial } \\
\text { estratigráfico }(80 \mathrm{~cm}) \text {. En el perfil } \\
\text { expuesto sólo se registran conchas y } \\
\text { restos de lobo. }\end{array}$ \\
\hline
\end{tabular}




\begin{tabular}{|c|c|c|c|c|}
\hline $\begin{array}{l}\text { NOMBRE* } \\
y^{\circ} \mathrm{N}^{\circ}\end{array}$ & $\begin{array}{l}\text { EXTENS. } \\
\mathrm{m}\end{array}$ & $\begin{array}{l}\text { ALTURA** }^{* *} \\
\text { msnm }\end{array}$ & DESCRIPCIÓN BIRD 1980 **** & DESCRIPCIÓN 2001-2003 \\
\hline Isabel 42 & $500 \times 30$ & $(1-4)$ & No reg. & $\begin{array}{l}\text { Conchales pequeños y restos dispersos } \\
\text { por erosión. } 25 \mathrm{~cm} \text { depósito máx. } \\
\text { Diversidad de artefactos líticos, óseos } \\
\text { y fauna (epífisis de guanaco con corte } \\
\text { perimetral y obsidiana verde). }\end{array}$ \\
\hline Isabel 43 & $20 \times 20$ & $(3-4)$ & No reg. & $\begin{array}{l}\text { Conchales y casas pozo. Depósito de } 20 \\
\text { cm aprox. Restos óseos de lobo, cetáceo } \\
\text { (cuña), ave y guanaco. } \\
\text { Justo bajo este sitio, desde la playa, se } \\
\text { observan varves. }\end{array}$ \\
\hline Isabel 44 & $250 \times 50$ & $(3-5)$ & No reg. & $\begin{array}{l}\text { Conchales y casas pozo, con materiales } \\
\text { dispersos en superficie (litico y óseo). } \\
\text { Posible chenque. Retocador. }\end{array}$ \\
\hline Isabel 45 & - & (5) & No reg. & $\begin{array}{l}\text { Dos o tres posibles casas pozo, conchal, } \\
\text { lascas dispersas en perfil expuesto, y } \\
\text { pocos restos óseos (aves y coruro). }\end{array}$ \\
\hline Isabel 46 & & $(10-12)$ & $\begin{array}{l}\text { Frente a sitio Isabel } 2, \\
\text { corral de pesca. }\end{array}$ & No reg. \\
\hline Isabel 47 & $100 \times 10$ & (1) & Entre sitios 1 y 2 & $\begin{array}{l}\text { Materiales dispersos (líticos, óseo y } \\
\text { conchas). }\end{array}$ \\
\hline Isabel 48 & $15 \times 2$ & (1) & Entre sitios Isabel 17 y 18 & $\begin{array}{l}\text { Conchales en perfil expuesto } 15 \mathrm{~cm} \\
\text { depósito. Restos de ave, cetáceo (costilla } \\
\text { cortada), un frag. de punzón. }\end{array}$ \\
\hline Isabel 49 & $50 \times 10$ & (1) & Entre sitios Isabel 17 y 18 & $\begin{array}{l}\text { Conchales parcialmente erosionados, } \\
\text { restos líticos (obsidiana verde) y óseos. } \\
\text { Depósito aprox. } 10 \mathrm{~cm} \text {. }\end{array}$ \\
\hline Isabel 50 & $20 \times 10$ & (6) & No reg. & $\begin{array}{l}\text { Conchales, materiales líticos (obsidiana } \\
\text { verde) y óseos. }\end{array}$ \\
\hline Isabel 51 & $100 \times 20$ & $(5-6)$ & No reg. & $\begin{array}{l}\text { Conchales disturbados y expuestos por } \\
\text { hoyos antrópicos. Depósito de aprox. } \\
30 \mathrm{~cm} \text {. Costilla de cetáceo con corte. } \\
\text { También se detectó una concentración de } \\
\text { lascas y conchas (maucho) en una terraza } \\
\text { sobre el sitio, aprox. } 10 \mathrm{msnm} \text {. }\end{array}$ \\
\hline Isabel 52 & - & (1) & No reg. & Conchal en perfil, material lítico y óseo. \\
\hline Isabel 53 & - & (1) & No reg. & Conchales, material lítico y óseo. \\
\hline Isabel 54 & - & (5) & No reg. & $\begin{array}{l}\text { Conchal en perfil, material lítico y óseo } \\
\text { (costillas de cetáceo). }\end{array}$ \\
\hline Isabel 55 & extenso & $(1-2)$ & No reg. & $\begin{array}{l}\text { Conchal extenso con restos del cráneo } \\
\text { de una ballena grande. Otros materiales } \\
\text { líticos y óseos. Depósito aprox. } 10 \mathrm{~cm} \text {. }\end{array}$ \\
\hline
\end{tabular}

* Corresponde a la denominación inicial dada por Bird (1980), con una numeración del 1 al 38. Luego, los nuevos hallazgos mantuvieron el nombre Isabel con un número consecutivo del 39 al 55 (Fig. 5).

** La primera estimación de altura es la indicada por Bird (1980) y entre paréntesis nuestra estimación de la altura sobre el nivel del mar.

*** Por conchal entendemos un montículo de conchas (sitio de vivienda según Bird) y por casa-pozo la depresión asociada generalmente a depósitos o montículo de conchas (rastro de toldo o house pit según Bird).

por Lovisato (Bird, 2012, p. 136), lo que constituye una opinión acerca de la magnitud del sitio, pero no resulta del todo claro que Bird haya observado el mismo sitio (ver más abajo). Se consigna que los viajeros de H.M.S. Challenger observaron que el espesor de algunos de los conchales de la isla era muy grande, a partir de lo que concluyeron una "great antiquity-possibly prior to the separation 
of Elizabeth Island from the mainland" (Tizzard et al. 1885 , p. 872). Esto es algo que ya no se puede mantener, pero sí persiste la certeza de la intensidad de las ocupaciones regulares.

\section{Sitio Isabel 25}

Se trabajó en un sitio con 15 estructuras monticulares localizado en Punta Silvestre y que corresponde al sitio \#25 de Bird, quien sondeó una unidad de excavación (fotografía en OrtizTroncoso, 1984, p. 124). El sitio se presentaba poco perturbado, con una cubierta de pasto casi continua y algunos arbustos. Hay una descripción realizada por Lovisato indicando una localización en el sector del paso Real en una especie de pradera tras pasar las barrancas altas (Lovisato, 1884) que es concordante. La morfología de este sitio es la misma que se ha observado en la zona de canales (ver Ortiz Troncoso, 1984).

Se realizó una trinchera en una pequeña estructura monticular ubicada sobre una terraza marítima baja, cubierta de pasto. El registro estratigráfico indica la presencia de una depresión de origen antrópico en la base del depósito (Fig. 6). Se recolectaron abundantes restos de ave, dominados por la presencia de cormoranes (Phalacrocorax sp.) y una proporción muy alta de pequeños fragmentos óseos no identificables, además de escasos restos de pinnípedos,
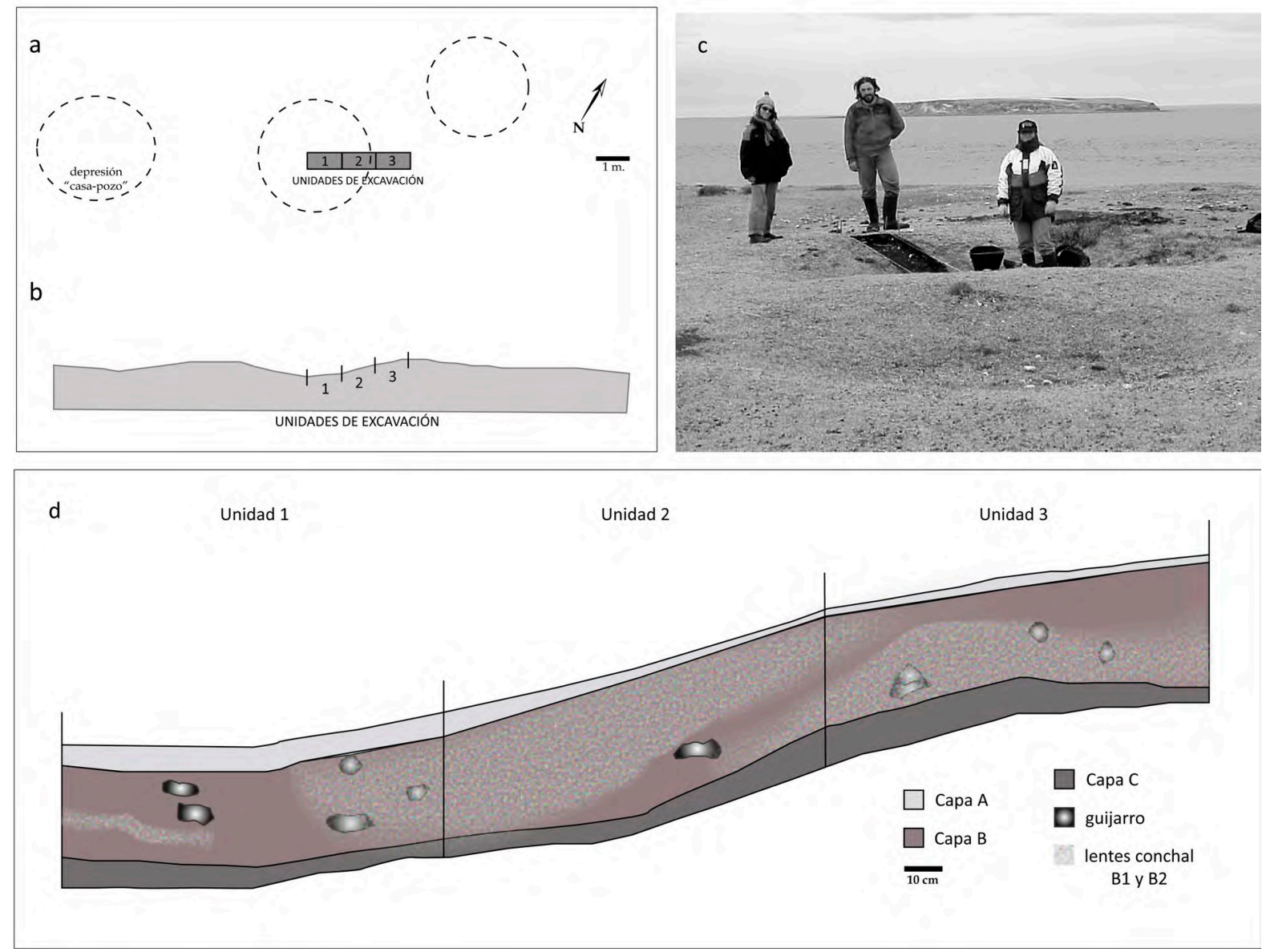

Fig. 6 a) Croquis de planta con tres depresiones tipo "casa-pozo" y trazado de la trinchera de excavación en Isabel 25; b) sección topográfica de montículos, depresión en el sector de excavación y unidades 1, 2 y 3; c) fotografía de la "casa-pozo" y excavación; d) perfil noroeste de la trinchera excavada. Capa A: arena café, raicillas, y escaso material cultural (conchas y restos óseos); Capa B: arena limosa café oscuro con conchas dispersas y lentes, guijarros $(5-10 \mathrm{~cm})$, material cultural y raíces. B1 y B2: lentes de conchal más denso con moluscos más enteros; Capa C: arena gris con guijarros medianos $(3-10 \mathrm{~cm})$ y estéril en términos culturales. 
pescado, moluscos y presencia de guanaco (Tabla 2). Los restos de cormorán presentaban mínima presencia de huellas de corte (Tabla 3). Además hay huellas sobre cuatro huesos de pato quetro (Tachyeres patachonicus) -dos sobre húmero, una sobre coracoides, una sobre escápula-, sobre seis huesos de Pinnipedia -tres sobre costillas, dos sobre falanges, una sobre metapodio-, una sobre hueso de cetáceo (corte de desbastamiento) $y$ tres sobre huesos indeterminados (fragmentos de diáfisis). Se registró un fragmento de punzón sobre hueso de ave.

El sondeo entregó una importante variedad de materiales líticos $(n=738)$. Entre los instrumentos formatizados el más frecuente es la raedera, le siguen los tajadores, percutores, bifaces, preformas de punta proyectil, raspadores, etc. (Tabla 4). Hay un número importante de núcleos, derivados de núcleo, desechos y percutores que atestiguan el desarrollo de actividades de talla in situ y la presencia de toda la cadena de manufactura de instrumentos de borde retocado.

Los sistemas de desbaste están enfocados a la obtención de lascas, pero se registra un núcleo laminar y también algunas láminas, en escasa frecuencia ( $n=14,1,9 \%)$. El método laminar se utiliza mayoritariamente sobre obsidiana verde, siguiendo los procedimientos descritos por Schidlowsky para sitios del Holoceno medio (Schidlowsky, 1999). El restante 60\% de lascas y $30 \%$ de desechos indeterminados incluye artefactos con distintos porcentajes de corteza y tipos de talones.

Las materias primas más abundantes son la obsidiana verde, pizarra, andesita y rocas silíceas. Otras rocas presentes entre los artefactos incluyen RGFO (sensu Charlin, 2009), riolita, rocas sedimentarias, cuarcita, esquisto, granito y algunas indeterminadas (Fig. 7). La presencia de una cuenta de vidrio nos ha permitido atribuir las ocupaciones del yacimiento al Holoceno tardíohistórico. El Lic. Adam Hajduk (CONICET) analizó la cuenta y, por el tipo de pátina y la forma en que se descascara, la determinó como de vidrio. Es de un color negro-gris muy oscuro, opaco. Por debajo de la pátina el color es mate. Las características del orificio también confirman que la cuenta es de vidrio. Lo más lógico es que se trate de una cuenta de "vidrio estirado", de
Tabla 2. Sitio Isabel 25. Pozo 1. Restos óseos.

\begin{tabular}{lc}
\cline { 2 - 2 } Lama guanicoe & NISP \\
Rodentia & 9 \\
Mammalia & 3 \\
Pinnipedia & 8 \\
Cetacea & 34 \\
Mamífero marino & 1 \\
Diomedea & 7 \\
Tachyeres patachonicus & 3 \\
Phalacrocorax sp. & 21 \\
Chloephaga sp. & 1.421 \\
Ave & 2 \\
Pez & 17 \\
Indet. & 25 \\
\hline Total & 1.697 \\
\hline
\end{tabular}

Tabla 3. Sitio Isabel 25. Pozo 1. Huellas de corte sobre Phalacrocorax sp.

\begin{tabular}{lc}
\cline { 2 - 2 } & Huellas de corte \\
\hline Húmero & 6 \\
Tibia-Tarso & 4 \\
Fémur & 6 \\
Escápula & 4 \\
Coracoides & 2 \\
Tarso-Metatarso & 2 \\
Ulna & 1 \\
Pelvis & 1 \\
\hline Total & 26 \\
\hline
\end{tabular}

un globo estirado en tubo y luego cortado. No hay posibilidad de acotar cronológicamente la cuenta, más allá de que es posterior al Contacto europeo (A. Hajduk, com. pers. 2003).

\section{$\underline{\text { Sitio Caleta Hook } 1}$}

En las cercanías del casco de la estancia se sondeó el sitio Caleta Hook 1, una concentración de conchales y depresiones localizada sobre una terraza alta. Se realizó un sondeo de 50 × 50 $\mathrm{cm}$ en el que se obtuvieron abundantes restos de Chloephaga sp., junto a otras aves y escasos restos de pescado (Tabla 5). La abundancia de 


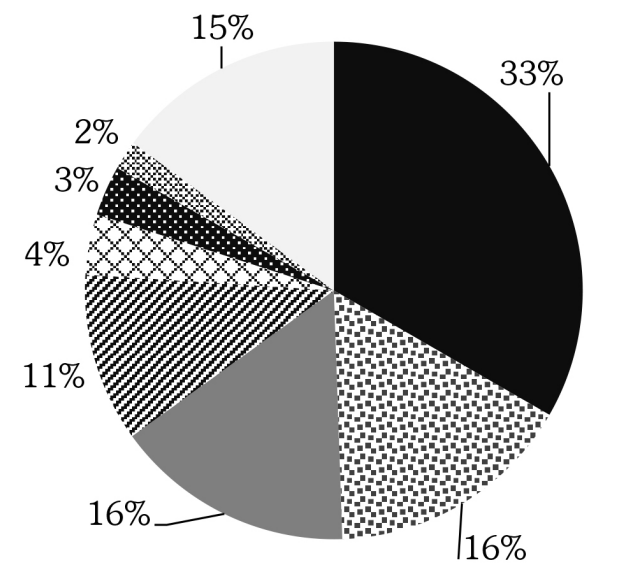

\author{
- obsidiana verde \\ s. pizarra \\ andesita \\ Z rocas silíceas \\ $\times$ RGFO \\ riolita \\ $\bowtie$ otras \\ indet.
}

Fig. 7. Porcentaje de materias primas del sitio Isabel 25.

Chloephaga es inusual (Tivoli \& Pérez, 2009, pp. 859-860). Se destacan una mandíbula de cricétido $^{11}$, dos falanges, dos húmeros $y$ un metapodio de Pinnipedia. Los restos de ave indeterminados, aunque principalmente vértebras y costillas, incluyen 10 anillos traqueales en posición anatómica, que indican cierta inmovilidad. La presencia de abundantes huellas de corte sobre restos de cauquén confirma el énfasis en esta presa (Tabla 6), con unos pocos casos de presencia de huellas sobre huesos de ave indeterminados (Tabla 7). Se fechó un coracoides de cauquén del sondeo 1 , recuperado a $50 \mathrm{~cm}$ de profundidad con un resultado de $1.235 \pm 40$ años $\mathrm{AP}$, d ${ }^{13} \mathrm{C}-22.0$ (Ua-24284).

Los restos están distribuidos en $50 \mathrm{~cm}$ de depósito arqueológico e incluyen escaso material lítico $(n=13)$. El único instrumento formatizado es un raspador y luego se recolectaron un núcleo, lascas y otros desechos. La materia prima más frecuente es la andesita, también se registra el uso de pizarra, sílice y otras rocas indeterminadas.

\section{Chenque 1 Isla Isabel}

Por otra parte, se realizaron sondeos en la cumbre de un drumlin en el lugar en que se concentraban rocas conformando una estructura tipo chenque. La presencia de este sitio fue informada por el Sr. Aladino Nicucheo y confirmada por la presencia de dos

11 Los hallazgos de roedor en la isla son conocidos al menos desde las observaciones de los naturalistas del H.M.S.
Tabla 4. Sitio Isabel 25.

Frecuencia y porcentaje de categorías de materiales líticos.

\begin{tabular}{|c|c|c|}
\hline Categoría & $\mathrm{N}^{\circ}$ & $\%$ \\
\hline Instrumentos & 20 & 2,5 \\
\hline punta proyectil & 1 & 0,1 \\
\hline preforma punta de proyectil & 1 & 0,1 \\
\hline Bifaz & 2 & 0,3 \\
\hline Raedera & 6 & 0,8 \\
\hline Raspador & 1 & 0,1 \\
\hline Cuchillo & 1 & 0,1 \\
\hline Muesca & 1 & 0,1 \\
\hline lasca retocada & 1 & 0,1 \\
\hline Tajador & 3 & 0,4 \\
\hline Percutor & 3 & 0,4 \\
\hline Restos de talla & 718 & 97,4 \\
\hline Núcleo & 11 & 1,5 \\
\hline guijarro astillado & 16 & 2,2 \\
\hline laja astillada & 8 & 1,1 \\
\hline Lasca & 445 & 60,3 \\
\hline Lámina & 14 & 1,9 \\
\hline Desecho & 224 & 30,4 \\
\hline Total & 738 & 100,0 \\
\hline
\end{tabular}

estructuras semejantes y muy disturbadas por acción antrópica previa (Fig. 8). Se recuperaron pequeños fragmentos óseos humanos y restos

Challenger (Tizzard et al. 1885, p. 872) y confirmados por los sondeos de Bird (1980, p. 81). 
Tabla 5. Caleta Hook 1. Pozo 1. Restos óseos. * = mayormente vértebras, costillas o fragmentos indeterminados.

\begin{tabular}{|c|c|c|c|c|c|c|c|}
\hline & $\mathrm{Cm}$ & $0-10$ & $10-20$ & $20-30$ & $30-40$ & $40-50$ & Total \\
\hline Pinnipedia & & - & 2 & 2 & - & 1 & 5 \\
\hline Cricetidae & & - & - & - & - & 1 & 1 \\
\hline Chloephaga sp. & & 3 & 6 & 66 & 32 & 90 & 197 \\
\hline Phalacrocorax sp. & & - & - & - & 1 & - & 1 \\
\hline Tachyeres patachonicus & & - & - & - & - & 4 & 4 \\
\hline Larus sp. & & - & - & - & - & 1 & 1 \\
\hline$A v e^{*}$ & & 64 & 89 & 43 & 112 & 243 & 551 \\
\hline $\mathrm{Pez}$ & & - & 6 & 4 & 15 & & 25 \\
\hline Indet. & & - & - & 3 & 1 & 1 & 5 \\
\hline Total & & 67 & 103 & 118 & 161 & 341 & 790 \\
\hline
\end{tabular}

líticos recolectados en superficie $(n=18)$ y en el pozo de sondeo 1 ( $n=22)$. El conjunto lítico es especialmente llamativo, pues se trata de un núcleo y derivados de núcleo tallados sobre materias primas de buena a muy buena calidad ${ }^{12}$. Se identificó una lasca secundaria de obsidiana verde, una lámina secundaria, ocho lascas y cinco desechos en RGFO (sensu Charlin, 2009). Además 15 lascas de un mismo nódulo de sílice gris oscuro y otras cuatro lascas y desechos sobre rocas silíceas. Se observaron pequeñas manchas de pigmento rojo en cinco piezas del pozo 1 , incluyendo la lámina, tres lascas secundarias de RGFO y un desecho de sílice gris oscuro.

\section{Sector Cabo Thórax y otros}

Se trabajó en Cabo Thórax, que se proyecta en el paso Pelican, en una extensa zona que corresponde a los sitios \#8 a \#12 de Bird. Allí se realizó la excavación de un pozo de sondeo de 50 x $50 \mathrm{~cm}$, que se identificó con la denominación Thórax 1. Está ubicado a unos 140 metros de la actual berma, en un montículo cónico con depósito de conchal de $45 \mathrm{~cm}$ de espesor, por sobre una capa de arena. Se fechó un coracoides de cormorán recuperado en el sondeo 1 entre 30 y $40 \mathrm{~cm}$ de profundidad con un resultado de $1.505 \pm 40$ años AP, $d^{13} \mathrm{C}-12.3$ (Ua-24287), con un posible efecto reservorio (ver arriba).

Los materiales líticos del sondeo se

12 El 22,5\% corresponde a rocas de buena calidad para la talla, $75 \%$ materias primas de buena a muy buena calidad y
Tabla 6. Caleta Hook 1. Huellas de corte sobre Chloephaga sp.

\begin{tabular}{lc}
\cline { 2 - 2 } & Huellas de corte \\
\hline Húmero & 7 \\
Fémur & 1 \\
Tibia-tarso & 3 \\
Escápula & 4 \\
Coracoides & 1 \\
Radio & 2 \\
Tarso-metatarso & 2 \\
\hline Total & 20 \\
\hline
\end{tabular}

Tabla 7. Caleta Hook 1. Huellas de corte sobre huesos de Ave [además hay huellas en diáfisis central de un radio de Tachyeres patachonicus].

\begin{tabular}{lc}
\cline { 2 - 2 } & Diáfisis central \\
\hline Carpo-metacarpo & 1 \\
Tibia-tarso & 1 \\
Tarso-metatarso & 1 \\
Indet & 4 \\
\hline Total & 7 \\
\hline
\end{tabular}

caracterizan por incluir solamente lascas y desechos indeterminados, distribuidos entre los 10 y $40 \mathrm{~cm}$ de profundidad. Una de las materias primas mejor representadas es la obsidiana verde y adicionalmente se recolectaron artefactos en rocas silíceas, pizarra, cuarcita, andesita y otras no identificadas. 


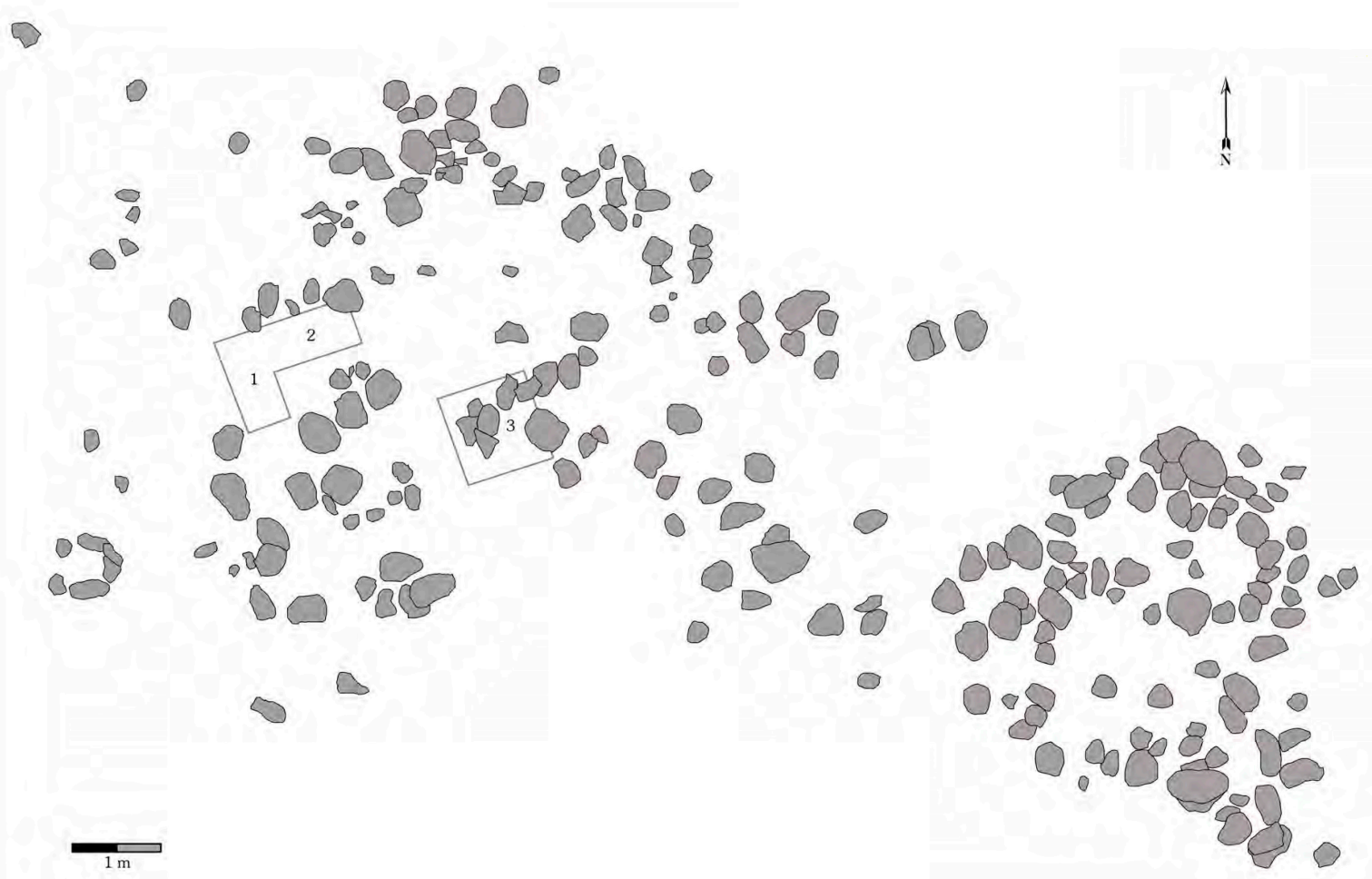

Fig. 8. Dibujo de planta de estructura Chenque 1 isla Isabel.

En el sector identificado con el sitio Isabel 12 de Bird se realizaron recolecciones superficiales dirigidas, recuperándose información tecnológica sobre la industria en obsidiana verde y otras rocas de buena a muy buena calidad (rocas silíceas y RGFO). La presencia de dos núcleos, seis láminas y lascas de distinto tipo indica la realización de actividades de desbaste de cierta complejidad tecnológica pero la muestra es demasiado incompleta para precisar $(n=37)$.

Igualmente se recuperaron algunos instrumentos que por aspectos morfo-tipológicos resultaban llamativos, como el caso de una punta de proyectil "tipo yámana" en el sitio Isabel 12. Pero más interesante es la recolección de bolas de boleadora en el sitio del interior Isabel $38(n=10)$. Entre los instrumentos formatizados se registran cuatro bolas con surco de distintos tipos (dos fusiformes, una esférica y una subesférica), dos pesas de red y un percutor en arista, predominando como materia prima del conjunto el gabro. Los instrumentos formatizados por retoque son dos raederas y un cuchillo.

\section{DISCUSIÓN}

\section{Procesos de formación}

Uno de los temas centrales de este proyecto se relaciona con la identificación de procesos de formación. Se realizaron transectas tafonómicas en todas las localidades, principalmente para evaluar el potencial de mezcla entre restos marítimos o transportados por el mar y restos depositados durante ocupaciones indígenas. Además, se realizaron observaciones específicas de tafonomía, particularmente acerca de la lluvia de huesos de pinnípedos en la costa (Borrero, 2004).

La evidencia de isla Isabel sirvió para destacar el tema de las transformaciones del registro arqueológico en escala supra-sitio. En dicha escala hay conjuntos de sitios afectados por la erosión retrocedente de los acantilados de la costa Este (Bird, 1980, p. 76). Sin embargo, aún es reconocible el sitio \#28, identificado ya en 1876 por la tripulación del Challenger. Esto significa que al menos los sitios en localizaciones más altas lograron mantenerse relativamente 
íntegros (y reconocibles) tras algo más de 100 años. La situación no es la misma para sitios más bajos o cercanos a la costa. Coppinger reportó que en 1879 The cliff was apparently breaking away in many places, exposing fresh sections of its face (Coppinger, 2007[1883], p. 39). Entre los importantes cambios registrados se observó que un sector reconocido como erosionado por Bird (1980, p. 78) era mucho más amplio en 2003. En ese sector se registró abundante material lítico pero no se recuperó material óseo. Por otra parte, no vimos evidencia arqueológica en la localización correspondiente al sitio \#27 de Bird, en la terraza más baja, lo que lleva a pensar que probablemente desapareció. Esto es concordante con que esa terraza está expuesta a la dinámica costera.

Bird observó muchas diferencias con respecto a los registros de Lovisato, hablando de una pérdida de hasta el $80 \%$ del mismo, pero nosotros vemos pocas diferencias con respecto a la previa descripción artística del Challenger. Dado que la identificación del locus de Lovisato (sensu Bird) es relativamente dudosa (Bird, 1980, p. 77), parecería defendible que el daño costero ha sido inferior al juzgado por Bird.

Ya mencionamos que los procesos de transformación antrópicos también incluyeron incendios, un proceso bien conocido para las costas patagónicas y fueguinas (Dixie, 1996[1880]). Por ejemplo, Narborough destacó que los habitantes de la isla "le prendieron fuego a la hierba de la orilla" (Anónimo, 2007[1711], p. 120). Es posible que al menos parte de las columnas superiores de micropartículas de carbón estudiadas en distintos sectores del sur del continente se refieran a procesos como éstos (Martinic, 2000; Huber et al. 2004; Mancini et al. 2005).

En Cabo Thórax existe una enorme concentración de materiales arqueológicos, que Bird categorizó en cuatro sitios (\#8, \#9, \#10 y \#11) (Bird 1980, p. 83). Durante nuestros trabajos, al haberse reducido la cubierta de champa y operado procesos de redepositación, todo el sector se presenta como un único sitio muy extendido. Como parte de la dinámica de ese sector, recordemos que Bird menciona haber visto "una pequeña ballena muerta, varada hace como un año alli”" (Bird, 1980, p. 83), a lo que agregamos nuevas evidencias tafonómicas de lluvia de huesos de mamíferos marinos post 1930s (Borrero, 2004, pp. 446-447). Asimismo Moseley destaca que The human débris is evidently of all ages, and I even found a sardine tin amongt it, perhaps left there by Cunningham (Moseley, 1892, p. 380).

Más allá de la línea de costa, los agentes biológicos de erosión y disturbación no parecen haber sido importantes en el pasado, pero sí en tiempos más recientes. Ha habido caballos en la isla por lo menos desde fines del siglo XIX, como los que entregaron a Duinsmuir, Vice-Cónsul británico en 1879 en Punta Arenas, a quien el gobierno chileno había rentado la isla (Coppinger, 2007[1883]). Hacia 1876-1877 H.L. Reynard, socio de Duinsmuir y Vice-Cónsul británico entre 1879 y 1897, llevó más de 300 ovejas a la isla, las que se multiplicaron rápidamente, aparentemente al punto de saturar el ambiente (Spears, 1895, p. 31; Childs, 1936, p. 93; Martinic, 1992, p. 539; Cook, 1998[1900], p. 78; Blake, 2003, p. 30). En 1936 el dueño de la isla, Sr. Pivcevic, invitó a Junius Bird a visitarla durante el período de esquila (Bird, 1980, p. 76), mostrando la importancia de las ovejas en la isla ya en el siglo XX. La presencia de aquellas en la isla ha tenido continuidad hasta la actualidad.

Con respecto a la acción de las corrientes debe mencionarse el registro de un asta de huemul (Hippocamelus bisulcus) y abundantes huesos de lobo marino en la superficie de diversos tramos de la costa, pero concentrados en la costa noroeste de la isla (Borrero, 2004). Las estructuras monticulares de la costa presentaban concentraciones de rodados y huesos de lobo en la parte deprimida, indicando que actuaron como trampas topográficas.

Carácter de las ocupaciones, geografía cultural y biogeografía

La arqueología que hemos registrado en la isla Isabel se refiere al Holoceno tardío. Ha sido propuesto que las ocupaciones de la isla Isabel fueron continuas (Ortiz Troncoso, 1971, p. 24), o que se explican dentro de un esquema logístico (Borrero, 2006). Tanto las observaciones de viajeros como los resultados de nuestras excavaciones indican una presencia humana relativamente intensa, pero difícil de considerar como constante, al punto que Cook menciona que la isla estaba "desierta" en 1897 (Cook, 1998[1900], p. 78). Lo que sí puede defenderse es 
que la isla Isabel formaba parte de un sistema de circulación canoera, probablemente haciendo uso complementario de recursos de islas (principalmente aves) y de tierra firme. La explotación logística de aves en la isla, quizá estacional, parece la mejor forma de explicar el registro arqueológico conocido. Esta es una situación semejante a la registrada en islas de Cabo de Hornos (Lefèvre, 1993-1994; Legoupil, 1993-1994).

Algunas peculiaridades de la geografía cultural adquieren importancia para explicar la movilidad humana en esta zona. La localización de la isla hace pertinente el tema biogeográfico. No sólo se trata de una importante isla continental, sino que se ubica aproximadamente en la zona de la separación de ambientes boscosos y esteparios, lo que significa un acceso a variedad de recursos, la mayoría de los cuales han sido registrados en los sitios de la isla. El lugar que ocupa la isla Isabel, dentro del esquema de interacciones entre cazadores de los mundos marítimo y terrestre es central, ya que es el territorio más oriental explotado regularmente por canoeros en tiempos históricos (Ortiz-Troncoso, 1984, p. 127; Emperaire, 2002[1958]), ubicado además en plena área Guaicurú (ver Martinic, 2006) y no muy lejos de los narrows del Estrecho. Igualmente Cunningham (1871, p. 150) habla de la isla como lugar de encuentro de "Patagones" y "canoe-men", lo que también surge de las observaciones de Darwin. En otras palabras, alli se registraron las evidencias de cohabitación entre Aonikenk y lo que los viajeros llamaban Fueguinos, que no necesariamente era gente de la isla de Tierra del Fuego, aunque sí eran canoeros (Borrero et al. 2011). Este es el núcleo de la zona en que se registraron hallazgos que en otras regiones patagónicas se presentan más segregados. Hallazgos realizados en la isla tanto de restos de guanaco como de huemul seguramente informan acerca de transporte humano $\mathrm{u}$ de otros agentes como las corrientes. Los restos de guanaco se presentan mayoritariamente en contextos arqueológicos. Además de los bienes ya mencionados, hay que recalcar que hay en la isla una conjunción de bolas, corte perimetral sobre huesos de guanaco, arpones y cuñas sobre hueso de mamífero marino, puntas de proyectil de "tipo yámana" y un probable chenque. Agreguemos la presencia de obsidiana negra y verde, que se suman a las evidencias previas obtenidas sobre ambos lados del Estrecho (Morello et al. 2012). Ya se ha destacado la observación de Narborough acerca de la presencia de individuos con arcos y pieles de guanacos. También hay sitios con recursos marítimos, de morfología semejante a la registrada en el hábitat de los canoeros. En conjunto con la señal mixta registrada en isótopos estables sobre huesos humanos de la costa continental del Estrecho (Borrero et al. 2001) y la obsidiana verde, este panorama marca la existencia de una zona aún poco acotada en la que características occidentales y orientales se superponen y mezclan. También hay restos de guanaco en sitios de la isla Dawson, un poco más al sur (Legoupil et al. 2011) y rocas de procedencia fueguina en la isla Magdalena (Labarca et al. 2014; Borrazzo et al. 2015).

Importa destacar que Narborough hace una mención de relevancia en términos de la circulación humana (Anónimo, 2007[1711], p. 122), "estaban en esta isla aguardando la oportunidad de que hubiese buen tiempo para ir a las otras islas a buscar pingüinos /y cormoranes de pecho blanco/". Esta observación lleva a ver a las tres principales islas del centro del Estrecho como interconectadas dentro de la geografía cultural indígena. La observación ofrecida por Darwin en su Diary acerca de individuos altos y de "fueguinos" (Darwin, 1988), también conecta el continente y la Isla Grande. De hecho un grupo de misioneros dirigido por Teófilo Schmid exploró en la Allen Gardiner diferentes posibles enclaves para una misión en 1858, concluyendo que la isla Isabel era el lugar ideal "atendida su posición intermedia entre los nómades marinos y los cazadores esteparios" (Martinic, 1992, p. 478). Esa misión finalmente no se concretó (Vignati, 1964, p. 110).

Fitz Roy había observado la escasa distancia que separaba "the neck of land separating /Otway Water/...from the Strait near Elizabeth Island" (Parker King, 1831, p. 163). Efectivamente, la cercanía de la isla con el istmo de Brunswick la ubica en la ruta de comunicación de menor costo con el mar de Otway (ver Di Grande et al. 1996, p. 400), quizá a través de río Pescado (Lista, 1975[1879], p. 63, también Morello et al. 2004). La existencia de lagunas en este istmo permite la posibilidad de que existieran senderos que cruzaran la península (Emperaire, 2002[1958], p. 92 refiere inclusive uno 
alejado del istmo), o porteos (Prieto et al. 2000, p. 88, ver también Bove, 2005[1883], p. 75).

Las ocupaciones de aproximadamente los últimos 200 años coinciden con un período de intensa actividad poblacional. Goñi sugirió que una reducción de la movilidad y una tendencia hacia un mayor sedentarismo relacionado con la introducción del caballo entre los Aonikenk generaron desplazamientos hacia el sur, incluyendo cruces del Estrecho. Estos desplazamientos estarían causados por las necesidades ecológicas de los caballos y otras derivadas del crecimiento demográfico en áreas cercanas al centro del estrecho de Magallanes (Goñi, 2013). Independientemente de la resolución de esta idea de Goñi, es defendible que las características de las ocupaciones implican una etapa de colonización efectiva del espacio, en un tiempo en el que situaciones similares están registradas en regiones vecinas. Esto no significa ocupaciones permanentes en la isla, sino que el uso de la misma aparece como plena y sistemáticamente integrada dentro de circuitos de movilidad humana.

\section{Importancia de las aves}

Con respecto a la ya mencionada importancia de los restos de aves en los sitios excavados, hay que recordar que las islas eran lugares clásicos de caza de éstas para navegantes y que abundan las referencias históricas a la importancia de las aves en Isabel e islas cercanas (cf. Meriais, 1847, p. 378; Cunningham, 1871, p. 153; Moseley, 1892 , p. 479; Alcazaba en Pastells, 1920; Sarmiento de Gamboa, 1950, p. 379, 387; Cook, 1998[1900], p. 77; Anónimo, 2007[1711], p. 122; Fitz Roy, 2009[1839], p. 105). Townsend registró hacia 1888, A rookery of Cassin terns occupied several acres, the nests being close together ...adjacent island of Santa Marta was largely occupied by white-breasted cormorants .. several acres (Townsend, 1910, p. 16). La isla Isabel también fue descripta como llena de upland geese ... which breed in large numbers on the island (Coppinger, 2007[1883], p. 38-39). Sin embargo, Bouganville (2005[1772], p. 174) avistó "sólo unas pocas" aves en diciembre de 1767, al igual que Lambart Price en 1875 (1877, p. 59). Asimismo Ibar Sierra no observó la "infinidad de pintadas aves" (Ibar Sierra,
(2002[1877]), p. 61) descritas por los viajeros, tan sólo algunos patos, cisnes y "canquenes" y no registró depósitos de guano. Explicó esta ausencia mediante una combinación de tácticas de escape al hombre y estacionalidad. La primera explicación tiene sentido en función de la larga historia de caza de aves por parte tanto de nativos como de recientes exploradores. Ya Moseley destacó que en 1876 young wild geese ... dodge behind a tuft of grass, and squatting closely under it are at once safe. It is quite impossible to find them.... disappears as if by magic (Moseley, 1892, p. 480).

Por supuesto, es de interés la dominancia arqueológica de aves (Lefèvre, 1989a, 2010; Rasmussen et al. 1994; Tivoli, 2010a, 2010b). Ante todo, hay que mencionar los casos de isla Escarpada en el mar de Skyring (Legoupil, 2000, p. 100ss.), Ponsomby (niveles superiores), Bahía Colorada (Lefèvre, 1997) y Punta Baja (Lefèvre, 1989b) en el mar de Otway, Bahía Buena (Lefèvre, 1989a), Punta Santa Ana en el Estrecho (Lefèvre, 2010, pp. 125-126; San Román, 2010), islas Dawson y Offing (Legoupil et al. 2011; Lefèvre \& Laroulandie, 2014) y CV6 en cabo Vírgenes (L'Heureux \& Franco, 2002). También hay presencia significativa de aves en sitios de la costa del estrecho de Magallanes en Tierra del Fuego (Bahamondes, 2004), en las islas Wollaston, Cabo de Hornos (Lefèvre, 1993-1994, p. 127) y en Túnel II en el canal Beagle (Piana \& Canale, 1995; Orquera \& Piana, 1999, pp. 80-81; Mameli \& Estevez Escalera, 2004, p. 139; Tivoli, 2010b). En sitios de Bahía Valentín también hay abundante presencia de aves (Vázquez et al. 2007, 2011; Zangrando et al. 2009; Tivoli, 2010b), así como en la isla de los Estados (Caviglia, 1987; Horwitz \& Weissel, 2011).

La proporción de aves a mamíferos es muy alta en muchas de estas acumulaciones, lo que puede hacer pensar en la existencia de procesos de contaminación. Sin embargo, hay que mencionar que las acumulaciones naturales de restos óseos de aves, que efectivamente son más abundantes en las zonas costeras que en el interior, se meteorizan y destruyen rápidamente (Cruz, 2005). En general presentan mayor diversidad taxonómica que la observada en acumulaciones como las mencionadas (Cruz, 2009). La presencia generalizada -aunque 
raramente abundante- de huellas de corte y el registro de huesos de ave decorados (Scheinsohn, 2010), sugieren que al menos una parte de estos registros obedece a acciones antrópicas.

\section{CONCLUSIONES}

La información recopilada sobre la isla Isabel indica su importancia histórica, etnográfica, arqueológica y biogeográfica. Esta isla ha estado intensamente integrada a la historia cultural magallánica al menos desde hace más de 2.000 años, sirviendo como un componente importante para la circulación humana tanto en tiempos prehistóricos como históricos. La situación revistada confirma que, dentro de la jerarquía de los ambientes del estrecho de Magallanes, pudo comportarse específicamente como un nexo entre los extremos ambientales y culturales definidos para esta región. Así lo confirman los registros históricos y los testimonios arqueológicos alli recuperados. Efectivamente, la presencia de restos de guanaco, un posible chenque y obsidiana negra integran a esta isla con los cambios en los cercanos ambientes terrestres, en tanto que la obsidiana verde, las cabezas de arpón, la fauna marina y la morfología de algunos sitios la hacen parte de los circuitos canoeros. Una conclusión inescapable es que los contextos arqueológicos de la isla Isabel responden a su situación de encrucijada de los mundos marino y terrestre.

\section{AGRADECIMIENTOS}

La presente investigación se realizó con el apoyo de MEC-PAI 80160111 y FONDECYT 1140939 de CONICYT, Chile, y PIP-CONICET 4596/96 Magallania II, Argentina.

Igualmente, se debe destacar el apoyo recibido por Milton Davidson, Aladino Nicucheo, Héctor y Carmen Agüero, y Sr. Blanco. Mateo Martinic B. contribuyó de diversas formas a la organización de estas campañas. Agradecemos el apoyo del British Museum, a Colin McEwan. A Danae Fiore, quien alertó acerca de la lámina publicada por Bove. A Ximena Senatore por su ayuda bibliográfica y al recordado Ariel Santana por su ayuda cartográfica. A Adam Hajduk por su análisis de la cuenta. Agradecemos a los colegas que participaron de las campañas de terreno, en orden alfabético: Manuel Arroyo-Kalin, Pedro Cárdenas, Ashley Lebner, Jacinthe Messier y Alfredo Prieto. Todos los materiales recuperados están depositados en el Centro de Estudios del Hombre Austral del Instituto de la Patagonia, Universidad de Magallanes.

\section{BIBLIOGRAFÍA}

Agassiz, J. L. (1872). Professor's Agassiz South American Expedition. Nature, 18(400), 229-231.

Agassiz, E. C. (1888). Louis Agassiz: His Life and Correspondence. Houghton Mifflin, Boston.

Anónimo (2007[1711]). El viaje de Sir John Narbrough al Mar del Sur. Un relato de diversos viajes $y$ descubrimientos recientes. EUDEBA, Buenos Aires.

Anrique, N. (1901). Diario de la goleta "Ancud" al mando del capitán de Fragata Don Juan Guillermos (1843) para tomar una posesión del Estrecho de Magallanes. Imprenta Litografia i Encuadernación Barcelona, Santiago de Chile.

Aragón, E., \& Franco, N. V. (1997). Características de rocas para la talla por percusión y propiedades petrográficas. Anales del Instituto de la Patagonia, 25, 187-199.

Arctowski, H. (1901). The Antarctic Voyage of the "Belgica" during the years 1897, 1898 and 1899. The Geographical Journal, 4(18), 353-394.

Auer, V. (1934). The Finnish expedition to Tierra del Fuego in 1928 - 1929. Acta Geographica, Societas Geographica Fenniae, 3-19, Helsinki.

Bahamondes, M. (2004). Las aves en la cultura selḱnam: estudio del registro arqueofaunístico de cuatro sitios de bahía Inútil (Tierra del Fuego). Magallania, 32, 163189.

Barros, J. M. (1988). La expedición de Narborough a Chile: nuevos antecedentes. Anales del Instituto de la Patagonia, 18, 35-59.

Belza, J. E. (1978). Romancero del topónimo fueguino. Instituto de Investigaciones Históricas Tierra del Fuego, Buenos Aires.

Bird, J. (1938). Antiquity and migrations of the early inhabitants of Patagonia. Geographical Review, 28(2), 250-275.

Bird, J. (1980). Investigaciones arqueológicas en la isla Isabel, estrecho de Magallanes. Anales del Instituto de la Patagonia, 11, 75-88.

Bird, M. (2012). Through Her Eyes. The Adventures of Margaret McKelvy Bird. Letters Edited by Her Son Harry Bird. Lulu Press, New York. 
Blake, J. L. (2003). A Story of Patagonia. The Book Guild Ltd., Sussex.

Borrazzo, K. B., Morello, F., Borrero, L. A., D'Orazio, M., Etchichury, M. C., Massone, M., \& De Angelis, H. (2015). Caracterización de las materias primas líticas de Chorrillo Miraflores y su distribución arqueológica en el extremo meridional de Fuego-Patagonia. Intersecciones en Antropología. Volumen Especial 5, "Materias primas líticas en Patagonia. Localización, circulación y métodos de estudio de las fuentes de rocas de la Patagonia argentino-chilena”, J. Alberti \& M. V. Fernández (Eds.), (pp. 155-167).

Borrero, L. A. (1998). Proyecto "Estudio de las colecciones almacenadas en el British Museum". British CouncilFundación Antorchas.

Borrero, L. A. (2004). Tafonomía regional: el caso de los pinnipedos. En M. T. Civalero, P. M. Fernández \& A. G. Guráieb (Eds.), Contra Viento y Marea. Arqueología de Patagonia (pp. 445-454). Buenos Aires: INAPLSAA.

Borrero, L. A. (2006). Proyecto "Visitas, intercambio y la "zona vacía”. Proyecto PICT-2006.2046, Agencia Nacional de Promoción de la Ciencia y la Tecnología.

Borrero, L. A., \& Franco, N. V. (2001). Las colecciones líticas del Museo Británico. Anales del Instituto de la Patagonia, 29, 207-210.

Borrero, L. A., Guichón, R. A., Tykot, R., Kelly, J., Prieto, A., \& Cárdenas, P. (2001). Dieta a partir de isótopos estables en restos óseos humanos de Patagonia austral. Estado actual y perspectivas. Anales del Instituto de la Patagonia, 29, 119-128.

Borrero, L. A., Martin, F. M. \& Barberena, R. (2011). Visits, "Fuegians," and Information Networks. En R. Whallon, W. A. Lovis \& R. K. Hitchcock (Eds.), Information and its Role in Hunter-Gatherer Bands (pp. 249-265). Los Angeles: The Cotsen Institute of Archaeology at UCLA.

Bouganville, L-A. (2005[1772]). Un viaje alrededor del mundo a bordo de la fragata real la Boudeuse y la urca Étoile, en 1766, 1767, 1768 y 1769. Buenos Aires: Eudeba.

Bove, G. (2005[1883]). Expedición a la Patagonia. Un viaje a las tierras y mares australes (1881-1882). Ediciones Continente, Buenos Aires.

Brassey, A. (1891). A Voyage in the 'Sunbeam'. Our Home in the Ocean for Eleven Months. J.W. Henry, St Louis.

Broussain, J. P. (2012). Cuatro relatos para un naufragio. Septiembre Ediciones, Santiago de Chile.

Brunton, E. V. (1994). The Challenger Expedition, 1872-
1876: A Visual Index. Palaeontology/Mineralogy Library. The Natural History Museum, London.

Bulkeley, J., \& Cummins, J. (2014 [1743]). Un viaje a los mares del sur en los años 1740-41. Buenos Aires: Eudeba.

Burkhardt, F., \& Smith, S. (Eds.) (1988). The Correspondence of Charles Darwin. Volumen 3, 1844-1846. Cambridge: Cambridge University Press.

Caviglia, S. E. (1987). Análisis del material faunístico del sitio Bahía Crossley. En A. Chapman (Ed.), La Isla de los Estados en la Prehistoria. Primeros Datos Arqueológicos (pp. 95-112). Buenos Aires: Eudeba.

Charlin, J. (2009). Estrategias de aprovisionamiento y utilización de las materias primas líticas en el campo volcánico Pali Aike (Prov. Santa Cruz, Argentina). British Archaeological Reports, International Series 1901, Archaeopress, Oxford.

Chevalier, F. (2000). Tours du Monde à la Voile. De Magellan a nous jours. Sélection du Reader's Digest S.A., Paris.

Childs, H. (1936). El Jimmy, a Patagonian Outlaw. Philadelphia-London: J. B. Lippincott.

Cook, F. A. (1998[1900]). Through the First Antarctic Night 1898-1899. A narrative of the voyage of the "Belgica" among newly discovered lands and over an unknown sea about the South Pole. Polar Publishing Company, Pittsburgh.

Cooper, J. M. (1967[1917]). Analytical and critical bibliography of the tribus of Tierra del Fuego and adjacent territory. Bulletin of the Smithsonian Institution, Bureau of American Ethnology , 63, Washington, D.C.

Coote, S. (2005[2003]). Drake. Pocket Books, London.

Coppinger, R. (2007[1883]). Four Years in Patagonia \& Polynesia. The Cruise of the Alert. September 1878-September 1882. Zagier \& Urruty, Ushuaia.

Corfield, R. (2005). The Silent Landscape. Discovering the world of the oceans in the wake of HMS Challenger's epic 1872 mission to explore the sea bed. John Murray, London.

Cruz, I. (2005). La representación de partes esqueléticas de aves. Patrones naturales e interpretación arqueológica. Archaeofauna, 14, 69-81.

Cruz, I. (2009). Tafonomía en escalas espaciales amplias: el registro óseo de las aves en el sur de Patagonia. En A. Acosta, D. Loponte \& L. Mucciolo (Eds.), Estudios tafonómicos y zooarqueológicos (pp. 15-34). Temas de Arqueología, Buenos Aires.

Cunningham, R. O. (1871). Notes on the natural history of the Strait of Magellan and west coast of Patagonia made during the voyage of H.M.S. Nassau in the 
years 1866, 67, 68, \& 69. Edinburgh.

Darwin, C. R. (1988). Charles Darwin's Beagle Diary. R. Darwin Keynes (Ed.), Cambridge University Press, Cambridge.

Di Grande, A., De Muro, S., \& Brambati, A. (1996). Il quaternario costero dela Peninsula Brunswick nei fogli "Villa Kon Aiken" e "Isla Isabel" (Stretto di Magellano - Cile). Il Quaternario. Italian Journal of Quaternary Sciences, 9(1), 399-404.

Dixie, F. (1996 [1880]). A través de la Patagonia. Ediciones de la Universidad de Magallanes, Punta Arenas.

Dumont D'Urville, J. C. (2011[1841]). “L'Astrolabe” y "La Zélée” en el Estrecho de Magallanes. Editorial Cuarto Propio, Providencia.

Emperaire, J. (2002[1958]). Los nómades del mar. Santiago de Chile: LOM Ediciones.

Fitz Roy, R. (1839). Narrative of the surveying voyages of His Majesty's Ships Adventure and Beagle between the years 1826 and 1836, describing their examination of the southern shores of South America, and the Beagle's circumnavigation of the globe. Proceedings of the second expedition, 1831-36, under the command of Captain Robert Fitz-Roy, R.N. Henry Colburn, London.

Fitz Roy, R. (2009[1839]). Viajes del Adventure y el Beagle. Primera expedición hidrográfica a las costas del Sur de Sudamérica. Mayo 1826-Octubre 1830. Tomo I, Zagier \& Urruty, Ushuaia.

Godley, E. J. (1965). Botany of the Southern Zone: Exploration to 1843. Tuatara, 13(3), 140-181.

Goñi, R. (2013). Reacomodamientos poblacionales de momentos históricos en el noroeste de Santa Cruz. Proyecciones arqueológicas. En A. F. Zangrando, R. Barberena, A. Gil, G. Neme, M. Giardina, L. Luna, C. Otaola, S. Paulides, L. Salgán \& A. Tivoli (Eds.), Tendencias teórico-metodológicas y casos de estudio en la arqueología de la Patagonia (pp. 389-396). Buenos Aires: Museo de Historia Natural de San Rafael.

Gould, S. J. (1984). Agassiz in the Galápagos. Hen's Teeth and Horse's Toes, pp. 107-119, W.W. Norton, New York.

Hawkesworth, J. (1773). An Account of the Voyages: Discoveries in the Southern Hemisphere. Vol. I. London.

Horwitz, V. D., \& Weissel, M. N. (2011). Arqueología de Isla de los Estados: La frontera de la abundancia. Los cazadores-recolectores del extremo oriental fueguino. En A. F. Zangrando, M. Vázquez \& A. Tessone (Eds.), Arqueología de Península Mitre e Isla de los Estados (pp. 143- 170). Buenos Aires: Publicaciones de la
Sociedad Argentina de Antropología.

Huber, U. M., Markgraf, V., \& Schäbitz, F. (2004). Geographic and temporal trends in Late Quaternary fire histories of Fuego-Patagonia, South America. Quaternary Science Reviews, 23, 1079-1097.

Ibar Sierra, E. (2002[1877]). Relación de los estudios hechos en el estrecho de Magallanes i la Patagonia austral durante los últimos meses de 1877, por el Ayudante del Museo Nacional de Chile Don Enrique Ibar Sierra (Naturalista de la comisión esploradora de la corbeta Magállanes). En M. Martinic (Ed.), Marinos de a caballo (pp. 61-116). Valparaíso: Universidad de Magallanes-Universidad de Playa Ancha.

Isla, F. I. (2002). Los exploradores de la Patagonia. De Magallanes a Fitz Roy. Universidad Nacional de Mar del Plata, Mar del Plata.

Labarca, R., Prieto, A., Sierpe, V., \& Morano, C. (2014). Ocupación e intercambio en las islas orientales del estrecho de Magallanes: resultados preliminares. Libro de resúmenes de las IX Jornadas de Arqueología de la Patagonia (p. 134).

Lambart Price, R. (1877). The Two Americas: An Account of Sport and Travel. With Notes on Men and Manners in North and South America. J.B. Lippincott, Philadelphia.

Lefèvre, C. (1989a). L'avifaune de Patagonie australe et ses relations avec l'homme au cours des six derniers millénaires. Diplôme de Doctorat (nouveau régime), Université de Paris I Panthéon-Sorbonne.

Lefèvre, C. (1989b). Les oiseaux. Punta Baja. En D. Legoupil (Ed.), Ethno-Archèologie dans les archipiels de Patagonie: Les nomades marins de Punta Baja (pp. 99-113). Paris: Éditions Recherche sur les Civilisations.

Lefèvre, C. (1993-1994). Las aves en los yacimientos del archipiélago del cabo de Hornos y del Seno Grandi. Anales del Instituto de la Patagonia, 22, 123-136.

Lefèvre, C. (1997). Les Oiseaux. En D. Legoupil (Ed.), Bahía Colorada (Île d'Englefield). Les primers chasseurs de mammifères marins de Patagonie australe (pp. 5964). Paris: Éditions Recherche sur les Civilisations.

Lefèvre, C. (2010). Birds in maritime hunter-gatherers subsistence: case studies from Southern Patagonia and the Aleutian Islands. En W. Prummel, J. T. Zeiler \& D. C. Brinkhuizen (Eds.), Birds in Archaeology Proceedings of the 6th Meeting of the ICAZ Bird Working Group in Groningen (pp. 117-130). Groningen: Barkhuis.

Lefèvre, C., \& Laroulandie, V. (2014). Avian Skeletal Part Representation: A Case Study from Offing 2, A Hunter-Gatherer-Fisher Site in the Strait of Magellan 
(Chile). International Journal of Osteoarchaeology, 24, 256-264.

Lefèvre, C., Lepetz, S., \& Legoupil, D. (2003). ¿Cazadores terrestres, cazadores marítimos? Explotación de recursos animales en el Locus 1 (Capítulo 2). En D. Legoupil (Ed.), Cazadores recolectores de Ponsonby (Patagonia Austral) y su paleoambiente desde VI al III milenio AC. Magallania, Tirada Especial, 31, 63116.

Legoupil, D. (1993-1994). El archipiélago del Cabo de Hornos y la costa Sur de la Isla Navarino: poblamiento y modelos económicos. Anales del Instituto de la Patagonia, 22, 101-121.

Legoupil, D. (2000). El sistema socioeconómico de los nómades del mar de Skyring (Archipiélago de Patagonia). Anales del Instituto de la Patagonia, 28, 81-119.

Legoupil, D., Béarez, P., Lefèvre, C., San Román, M., \& Torres, J. (2011). Estrategias de subsistencia de cazadores recolectores de isla Dawson (estrecho de Magallanes) durante la segunda mitad del Holoceno: primeras aproximaciones. Magallania, 39(2), 153-164.

L'Heureux, G. L., \& Franco, N. V. (2002). Ocupaciones humanas en el área de Cabo Vírgenes (Provincia de Santa Cruz, Argentina). El sitio Cabo Vírgenes 6. Anales del Instituto de la Patagonia, 30, 183-201.

Linklatter, E. (1974). The Voyage of the Challenger. Cardinal, London.

Lipschutz, A. (1950). On the Reliability of Some Written Sources of the Seventeenth and Eighteenth Centuries. American Anthropologist, 52(1), 123-126.

Lista, R. (1975 [1879]). Mis exploraciones y descubrimientos en la Patagonia: 1877-1880. Marymar, Buenos Aires.

Lovisato, D. (1884). Appunti etnografici con accenni geologici sulla Terra del Fuoco. Cosmos, 8(IV), 97-108.

MacDouall, R. N. (1833). Narrative of a voyage to Patagonia and Tierra del Fuego through the Straits of Magellan, in H.M.S. Adventure and Beagle, in 1826 and 1827. London: Renshaw and Rush.

Magazzù, G., Panella, S., \& Decembrini, F. (1996). Seasonal variability of fractioned biomass and primary production in the Straits of Magellan. Journal of Marine Systems, 9, 249-267.

Mameli, L., \& Estévez Escalera, J. (2004). Etnoarqueozoología de aves: el ejemplo del extremo sur americano. Treballs D'Etnoarqueología 5. Universidad Autónoma de Barcelona y Consejo Superior de Investigaciones Científicas CSIC, Madrid.

Mancini, M. V., Páez, M., Prieto, A., Stutz, S., Tonello, M., \& Villanova, I. (2005). Mid-Holocene climatic variability reconstruction from pollen records $\left(32^{\circ}-52^{\circ} \mathrm{S}\right.$, Argentina). Quaternary International, 132(1), 47-59.

Marangunic, C. (1974). Los depósitos glaciales de la Pampa magallánica. Revista Geográfica de Chile Terra Australis, 22-23, 5-12.

Marley, D. F. (2008). Wars of America: A Chronology of Armed Conflict in the Western Hemisphere, 1492 to the Present, Vol. I. ABC-CLIO Inc, Santa Bárbara.

Martinic, M. (1984). Noticia histórica sobre una prospección arqueológica realizada por Junius Bird a lo largo de la costa nororiental del estrecho de Magallanes. Anales del Instituto de la Patagonia, 15, 43-46.

Martinic, M. (1992). Historia de la región magallánica. 2 volúmenes. Punta Arenas: Universidad de Magallanes.

Martinic, M. (1999). Cartografía Magallánica. 1523-1945. Ediciones de la Universidad de Magallanes, Punta Arenas.

Martinic, M. (2000). Última Esperanza en el tiempo. Punta Arenas: Universidad de Magallanes y Universidad de Playa Ancha.

Martinic, M. (2006). Consideraciones sobre la etnografía de la Patagonia austral continental. El caso del grupo Guaicurú. Actas del XVI Congreso de Arqueología Chilena (pp. 187-192). Tomé.

Martinic, M. (2012). Los holandeses en las islas de los pingüinos (1599-1615). Magallania, 40(2), 7-22.

Meade, R. W. (1897). A winter voyage through the Straits of Magellan. The National Geographic Magazine, 8(5), 129-142.

Meriais, P. (1847). Traversée du détroit de Magellan, et observations sur les Patagons et les Feugiens [sic]. Nouvelles Annales des Voyages et des Sciences Géographiques, Tome I: 377-392. Paris: Editorial Arthus Bertrand.

Morello, F., San Román, M., \& Prieto, A. (2004). Obsidiana verde en Fuego-Patagonia: distribución y estrategias tecnológicas. En M. T. Civalero, P. M. Fernández \& A. G. Guráieb (Eds.), Contra Viento y Marea. Arqueología de Patagonia (pp. 149-166). Buenos Aires: INAPL-SAA.

Morello, F., Borrero, L., Massone, M., Stern, C., García-Herbst, A., McCulloch, R., Arroyo-Kalin, M.,... \& Cárdenas, P. (2012). Hunter-gatherers, biogeographic barriers and the development of human settlement in Tierra del Fuego. Antiquity, 86, 71-87.

Moreno, F. P. (1969[1879]). Viaje a la Patagonia austral. Buenos Aires: Solar/Hachette.

Moseley, H. N. (1892). Notes by a Naturalist: An Account of Observations made during The Voyage of H.M.S. 
"Challenger" round the World in the Years 18721876. London: T. Werner Laurie, Ltd.

Organ, M. K. (Ed.) (1994). Conrad Martens: journal of a voyage from England to Australia aboard HMS Beagle and HMS Hyacinth 1833-35. State Library of NSW Press, Sydney.

Orquera, L. A., \& Piana, E. L. (1999). Arqueología de la Región del Canal Beagle (Tierra del Fuego, República Argentina). Buenos Aires: SAA.

Ortiz Troncoso, O. (1971). Antecedentes históricos y prospección arqueológica de las islas Isabel, Santa Marta, Magdalena y Contramaestre (Estrecho de Magallanes). Anales del Instituto de la Patagonia, 2(1-2), 20-27.

Ortiz Troncoso, O. (1984). Arqueología del Estrecho de Magallanes y canales del Sur de Chile. Las Culturas de América en la Época del Descubrimiento (pp. 113129). Madrid: Ediciones Cultura Hispánica.

Parker King, P. (1831). Some observations upon the geography of the Southern Extremity of South America, Tierra del Fuego, and the Strait of Magalhaens. Journal of the Royal Geographical Society of London, 1, 155-175.

Pastells, P. (1920). El descubrimiento del Estrecho de Magallanes. Suc. de Rivadeneyra, Madrid.

Piana, E. L., \& Canale, G. (1995). Túnel II: un yacimiento de la Fase Reciente del Canal Beagle. Relaciones de la Sociedad Argentina de Antropología, 19, 363-389.

Pisano, E. (1977). Fitogeografia de Fuego-Patagonia chilena. I. Comunidades vegetales entre las latitudes $52^{\circ}$ y $56^{\circ}$ S. Anales del Instituto de la Patagonia, 8, 121-250.

Poletti Formosa, R. R. (1979). La primera expedición hidrográfica inglesa al confín austral americano (1826-1830). Instituto de Publicaciones Navales, Buenos Aires.

Prieto, A., Chevallay, D., \& Ovando, D. (2000). Los pasos de indios en Patagonia austral. Desde el país de los gigantes. Perspectivas arqueológicas en Patagonia (pp. 87-94). Río Gallegos: UNPA.

Quiroz, D., Carreño, G., \& De La Fuente, P. (2016). El procesamiento de ballenas varadas en las costas de la patagonia occidental (a propósito de un grabado de mediados del siglo XIX). Magallania, 44(1), 57-72.

Racovitza, E. (1998). Hacia el Sur. Por Patagonia y hacia el Polo Sur. Ediciones Universidad de Magallanes, Punta Arenas.

Rasmussen, P. C., Humphrey, P. S., \& Péfaur, J. E. (1994). Avifauna of a Beagle channel Archaeological sites. Occassional Papers of the Museum of Natural History of Kansas, 165, 1-41.
Riso Patrón, L. (1924). Diccionario Jeográfico de Chile. Imprenta Universitaria, Santiago.

Rolfo, M., \& Ardrizzi, G. (2007). Patagonia \& Tierra del Fuego. Nautical Guide. 2nd. Edition. Editrici Incontri Nautici, Roma.

San Román, M. (2010). La explotación de recursos faunísticos en el sitio Punta Santa Ana 1: Estrategias de subsistencia de grupos de cazadores mérinos tempranos de Patagonia meridional. Magallania, 38(1), 183-198.

San Román, M., Salas, K., \& Fontugne, M. (2009). Primeros avances en la reconstrucción de secuencias de ocupación de cazadores recolectores marinos en el estrecho de Magallanes, Patagonia meridional. En F. S. M. Salemme, M. Álvarez, E. Piana, M. Vázquez \& E. Mansur (Eds.), Arqueología de Patagonia: una mirada desde el último confín (pp. 35-45). Ushuaia: Utopías.

Santana, A., Calderón, J., \& Butorovic, N. (2001). Características climáticas del área de Bahía Laredo, Magallanes, Chile. Anales del Instituto de la Patagonia, Serie Ciencias Naturales, 29, 55-68.

Sarmiento de Gamboa, P. (1950). Viajes al Estrecho de Magallanes. 1579-1584. Volumen II. Emecé Editores, Buenos Aires.

Scheinsohn, V. (2010). Hearts and Bones. Bone Raw Material Exploitation in Tierra del Fuego. BAR International Series 2094. Oxford: Archaeopress.

Sielfeld, W. (1983). Mamíferos marinos de Chile. Santiago de Chile: Ediciones de la Universidad de Chile.

Sielfeld, W., Venegas, C., Atalah, A., \& Jones, J. (1978). Prospección de otáridos en las costas de Magallanes. Anales del Instituto de la Patagonia, 9, 157-169.

Spears, J. R. (1895). The Gold Diggings of Cape Horn. London: G. P. Putnam's Sons.

Spry, W. J. J. (1876). The cruise of Her Majesty's Ship Challenger: voyages over many seas, scenes in many lands. London: Sampson Low, Marston, Searle \& Rivington.

homson, Sir C. W., \& Murray, J. (1895). A Summary of the Scientific Results of the Voyage of H.M.S. Challenger during the Years 1873-76. Eyre \& Spottiswood, London.

Tivoli, A. M. (2010a). Temporal trends in avifaunal resource management by prehistoric sea nomads of the Beagle Channel region (southern South America). En W. Prummel, J. T. Zeiler \& D. C. Brinkhuizen (Eds.), Birds in Archaeology. Proceedings of the 6th Meeting of the ICAZ Bird Working Group. Groningen Archaeological Studies, 10, 131-140.

Tivoli, A. M. (2010b). Las Aves en la organización 
socioeconómica de cazadores-recolectorespescadores del extremo sur sudamericano. Tesis de Doctorado, Universidad de Buenos Aires.

Tivoli, A. M., \& Pérez, A. F. (2009). Rendimiento económico del cauquén común (Chloephaga picta, Familia: Anatidae). En M. Salemme, F. Santiago, M. Álvarez, E. Piana, M. Vázquez \& E. Mansur (Eds.), Arqueología de Patagonia: una mirada desde el último confín, Tomo II (pp. 853-864). Ushuaia: Utopías.

Tizzard, T. H., Moseley, H. N., Buchanan, J. Y., \& Murray, J. (1885). Narrative of the Cruise of H.M.S. Challenger with a General Account of the Scientific Results of the Expedition. Parts first and Second. London: Longmans \& Co.

Townsend, C. H. (1910). A Naturalist in the Straits of Magellan. The Popular Science Monthly, July, pp. 5-18.

Vargas de Ponce, J. de (1788). Relación del último viage al Estrecho de Magallanes de la fragata de su Majestad Santa María de la Cabeza en los años de 1785 y 1786. Viuda de Ibarra, Hijos y Compañía, Madrid.

Vázquez, M. M., Zangrando, A. F. J., Tessone, A., Ceraso, A., \& Sosa, L. (2007). Arqueología de Bahía Valentín (Península Mitre, Tierra del Fuego): Nuevos resultados y perspectivas. En F. Morello, M. Martinic, A. Prieto \& G.
Bahamonde (Eds.), Arqueología de Fuego-Patagonia. Levantando piedras, desenterrando huesos... y develando arcanos (pp. 755-766). Punta Arenas: Ediciones CEQUA.

Vázquez, M., Zangrando, F., Tessone, A., \& Ceraso, A. (2011). Arqueología de la costa meridional de península Mitre. En Zangrando, A.F., M. Vázquez \& A. Tessone (Eds.), Arqueología de Península Mitre e Isla de los Estados (pp. 203- 230). Buenos Aires: Publicaciones de la Sociedad Argentina de Antropología.

Vignati, M. A. (1964). Comentarios. En T. Schmid, Misionando por Patagonia Austral. 1858-1865, Usos y costumbres de los indios patagones (pp. 85-116). Buenos Aires: Academia Nacional de la Historia.

Yelverton, D. E. (2004). Quest for a phantom strait. The saga of the Pioneer Antarctic Peninsula Expeditions 1897-1905. Guildford: Polar Publishing.

Zangrando, A. F. J., Tessone, A., \& Vázquez, M. M. (2009). El uso de espacios marginales en el Archipiélago Fueguino: implicaciones de la evidencia arqueológica de Bahía Valentín. En M. Salemme, F. Santiago, M. Álvarez, E. Piana, M. Vázquez \& E. Mansur (Eds.), Arqueología de Patagonia: una mirada desde el último confín, Tomo I (pp. 47-62). Ushuaia: Utopías. 